\section{Pacific Northwest}

National Laboratory

Operated by Battelle for the

U.S. Department of Energy

\title{
Using DUSTRAN to Simulate Fog- Oil Dispersion and Its Impacts on Local Insect Populations at Ft. Hood: Final Report
}

\author{
J. P. Rishel \\ E. G. Chapman \\ F. C. Rutz \\ K. J. Allwine
}

December 2006

Prepared for the U.S. Department of Energy under Contract DE-AC05-76RL01830 


\title{
DISCLAIMER
}

This report was prepared as an account of work sponsored by an agency of the United States Government. Neither the United States Government nor any agency thereof, nor Battelle Memorial Institute, nor any of their employees, makes any warranty, expressed or implied, or assumes any legal liability or responsibility for the accuracy, completeness, or usefulness of any information, apparatus, product, or process disclosed, or represents that its use would not infringe privately owned rights. Reference herein to any specific commercial product, process, or service by trade name, trademark, manufacturer, or otherwise does not necessarily constitute or imply its endorsement, recommendation, or favoring by the United States Government or any agency thereof, or Battelle Memorial Institute. The views and opinions of authors expressed herein do not necessarily state or reflect those of the United States Government or any agency thereof.

\author{
PACIFIC NORTHWEST NATIONAL LABORATORY \\ operated by \\ BATTELLE MEMORIAL INSTITUTE \\ for the \\ UNITED STATES DEPARTMENT OF ENERGY \\ under Contract DE-AC05-76RL01830
}




\title{
Using DUSTRAN to Simulate Fog-Oil Dispersion and Its Impacts on Local Insect Populations at Ft. Hood:
} Final Report

\author{
J. P. Rishel \\ E. G. Chapman \\ F. C. Rutz \\ K. J. Allwine
}

December 2006

Prepared for the U.S. Department of Energy

under Contract DE-AC05-76RL01830

Pacific Northwest National Laboratory

Richland, Washington 99352 


\section{Summary}

Smokes and obscurants (S\&O) are important screening agents used during military training exercises on many military installations. Although the use of S\&O is subject to environmental laws, the fate and effects of S\&O on natural habitats are not well documented. One particular concern is the impact S\&O may have on local insect populations, which can be important components of terrestrial food chains of endangered species. Fog-oil (FO) is an S\&O that is of particular concern. An important part of assessing potential ecosystem impacts is the ability to predict downwind FO concentrations.

This report documents the use of the comprehensive atmospheric dispersion modeling system DUST TRANsport (DUSTRAN) to simulate the downwind transport and diffusion of a hypothetical FO release on the U.S. Army installation at Ft. Hood, TX. FO is used as an obscurant during certain training exercises at Ft. Hood, which is home to two endangered migratory avian species - the black-capped vireo and golden-cheeked warbler-from April to August. These birds forage on local insect populations, some of which potentially could be affected by FO releases.

Meteorological and source-term inputs required for DUSTRAN are explained, and representative values for the Ft. Hood site are presented. These values are used in simulating a hypothetical FO release. Modeled concentration results are compared with toxicological thresholds developed by project biologists at Pacific Northwest National Laboratory for certain insect types. Simulated results suggest that FO impacts to specific insect types, if any, will occur very near the source. To further support this finding, the conservative, straight-line Gaussian plume equation is used to estimate maximum downwind distances of possible toxicological effects for common meteorological stability classes. Conservative results indicate that impacts are likely to be within 400 meters of the FO source.

Several advanced analysis topics are reviewed that, in conjunction with the DUSTRAN User's Guide (Allwine et al. 2006), can be used to further investigate FO releases and their potential toxicological impacts. Specific guidance is provided on adjusting concentration levels and contour colors within the DUSTRAN modeling system; such functionality can be useful for identifying and plotting lethal-dose concentrations that cause a toxicological response in specific insect types. The "Polygon Layer Creator" utility is introduced and can be used to create polygons (i.e., areas) that represent insect populations for specific insect types. These polygons can be added and displayed within the DUSTRAN modeling system, and the area shared with model-calculated concentration contours can be determined. A sample stepwise procedure for setting up such a query is presented in Appendix B.

\section{Reference}

Allwine, KJ, FC Rutz, WJ Shaw, JP Rishel, BG Fritz, EG Chapman, BL Hoopes, and TE Seiple. 2006. DUSTRAN 1.0 User's Guide: A GIS-Based Atmospheric Dust Dispersion Modeling System.

PNNL-16055, Pacific Northwest National Laboratory, Richland, WA. 



\section{Acronyms}

AGL

ASOS

CALMET

CALPUFF

CERL

DoD

DOE

DUSTRAN

EPA

FID

FO

GIS

ICAO

LD

LST

NOAA

PNNL

SERDP

S\&O

TA

VBA

WMO above ground level automated surface observation station

CALifornia METeorological model

CALifornia PUFF model

Construction Engineering Research Laboratory

Department of Defense

U.S. Department of Energy

DUST TRANsport

U.S. Environmental Protection Agency

Feature ID (option)

Fog-Oil

Geographical Information System

International Civil Aviation Organization

Lethal Dose

local standard time

National Oceanic and Atmospheric Administration

Pacific Northwest National Laboratory

Strategic Environmental Research and Development Program

Smokes and Obscurants

Training Area

Visual Basic for Applications

World Meteorological Organization 



\section{Contents}

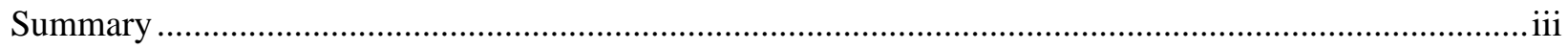

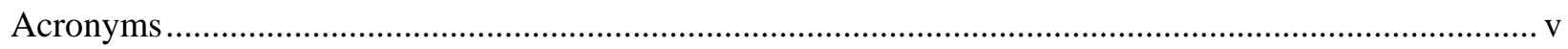

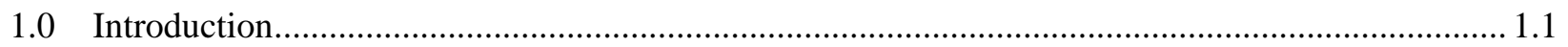

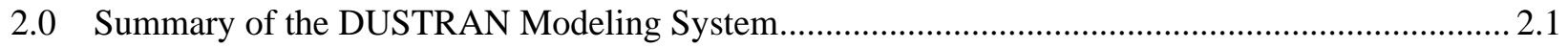

3.0 DUSTRAN Representation of Ft. Hood: Site Overview and Input Specifications ........................ 3.1

3.1 Meteorological Input Specification …................................................................................ 3.2

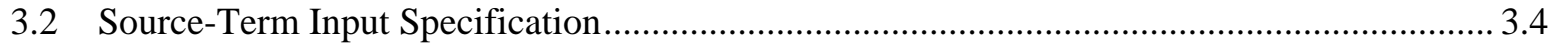

4.0 Sample Fog-Oil Release Simulation at Ft. Hood........................................................................ 4.1

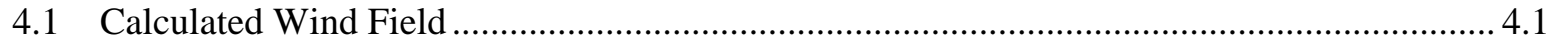

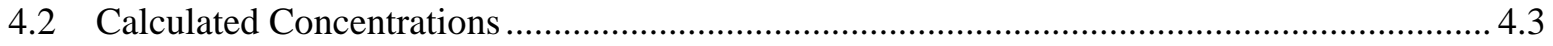

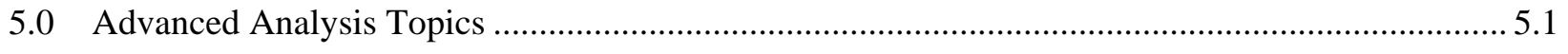

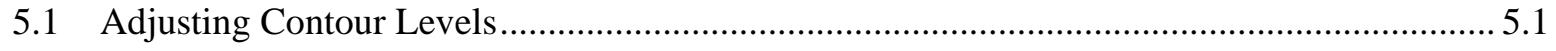

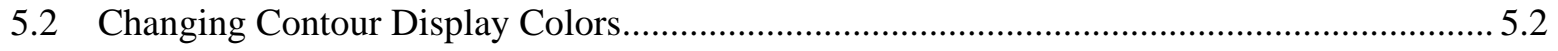

5.3 Using the Polygon Layer Creator Tool to Create Insect Populations ..................................... 5.3

5.3.1 Starting the Polygon Layer Creator ............................................................................ 5.3

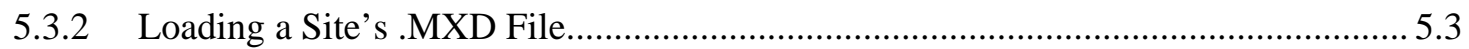

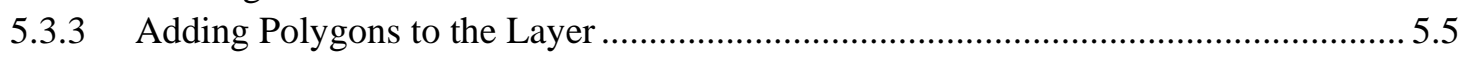

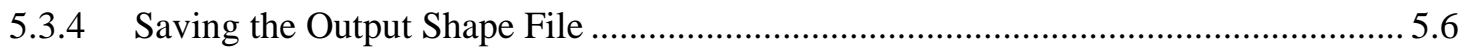

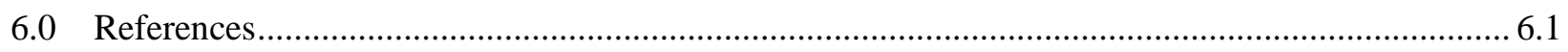

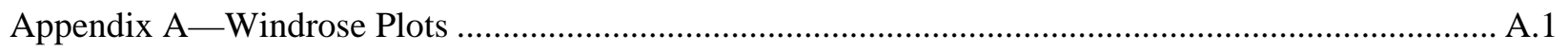

Appendix B—Calculating the Shared Area Between Polygons ...........................................................1 


\section{Figures}

3.1. The Ft. Hood Site Within the DUSTRAN/ArcMap Interface with Various Layers Labeled, Including Boundaries for FO Training Areas (TA 8, 35, 36) and Specific Endangered Bird Habitats.

4.1. 0700 LST Wind Field at 10 Meters Above Ground Level (AGL) for Sample April 25, 2005, FO Simulation at Ft. Hood.

4.2. Zoomed-in View of the 0700 LST Wind Field Near TA 36.

4.3. One-hour (0800-0900 LST) Average Concentrations from a Hypothetical FO Release Within Training Area 36

4.4. Average Concentrations Predicted from Straight-Line Gaussian Plume Model (Turner 1994) for a Ground-Level Release Using a Wind Speed of $2.5 \mathrm{~m} / \mathrm{s}$ and a Source Emission Rate of $57 \mathrm{~g} / \mathrm{s}$.

5.1. The Cal.par File for the Ft. Hood Site

5.2. The "Contour Properties" Window for each Contour Level can be Adjusted for Color and Width by Selecting the Contour Level Within "Layout View” in ArcMap

5.3. Ft. Hood .mxd File Loaded into the Polygon Layer Creator Utility .

5.4. Grid Code Input Window for Specifying Numbers that Represent Specific Insect Types or Populations

5.5. A Series of Polygons Created Within the Layer Creator Utility; each Polygon Represents an Insect Population Count

\section{Tables}

3.1. Location Information for ASOS Site Providing Hourly Meteorological Data ....

3.2. Sample "Single Observation" Meteorological Data Used in a Hypothetical DUSTRAN Simulation.

3.3. Sample FO Source-Term Characteristics for Use in DUSTRAN. 


\subsection{Introduction}

Smokes and obscurants (S\&O) are important screening agents used in Army troop maneuvers and are commonly used during training activities. Although the use of S\&O is subject to environmental laws, the fate and effects of S\&O on natural habitats are not well documented. One particular concern is the impact S\&O may have on insects, which can be important components of terrestrial food chains of endangered species.

Recently, concerns over S\&O impacts to insect populations have gained credibility. Studies at the U.S. Department of Energy (DOE) Pacific Northwest National Laboratory (PNNL) suggest that the larval and/or adult forms of several insect species are adversely affected when exposed to field concentrations of fog-oil (FO) - a commonly used S\&O. A better understanding of the effects that FO has on insect populations will allow installation trainers, natural resource managers, and U.S. Environmental Protection Agency (EPA) and U.S. Fish and Wildlife Service regulators to make informed decisions about FO use on installations. It is widely recognized that an important part of assessing potential ecosystem impacts is the ability to predict downwind FO concentrations.

This report documents the use of DUSTRAN (Version 1.0), an advanced Geographical Information System (GIS)-based dispersion modeling system, to simulate the downwind transport and diffusion of hypothetical FO releases. The model-predicted concentrations and exposures, when coupled with empirically derived toxicological response functions for specific insect types, can be used as a tool to investigate FO impacts on local insect populations that may be of importance to endangered bird species. Ft. Hood, a U.S. Army installation located approximately 60 miles north of Austin, TX, is used to demonstrate this application of DUSTRAN. Ft. Hood uses FO as an obscurant during certain training exercises. Two endangered migratory avian species - the black-capped vireo and golden-cheeked warbler-reside on the military installation from April to August. These birds forage on local insect populations, some of which have the potential to be affected by FO releases.

The report begins with a brief overview of the DUSTRAN modeling system. The Ft. Hood DUSTRAN site is then presented, along with a detailed discussion of meteorological conditions and source-term characteristics that are unique to Ft. Hood and are important for realistic simulations in DUSTRAN. A sample simulation using these model inputs is then presented, including an examination of resulting FO concentrations. Finally, advanced DUSTRAN analysis tools and techniques are presented that can be used to further examine and quantify FO effects on local insect populations.

Although this report focuses on simulations of FO releases at Ft. Hood, it is important to recognize that DUSTRAN and the techniques outlined here can be used to address other issues related to air-quality dispersion modeling and ecosystem impacts. 


\subsection{Summary of the DUSTRAN Modeling System}

DUSTRAN was developed under the U.S. Department of Defense's (DoD) Strategic Environmental Research and Development Program (SERDP) to create an atmospheric dispersion modeling system to assist the DoD in addressing particulate air quality issues at military training and testing ranges (Allwine et al. 2004; Allwine et al. 2006). Although coupled with a dust-emissions module for simulating emissions from vehicular and windblown dust applications (hence the name DUSTRAN—short for dust transport), DUSTRAN can be used more generally to simulate the downwind transport, diffusion, and deposition of any particulate or gaseous species.

Fundamental to DUSTRAN is the CALifornia PUFF (CALPUFF) modeling system-a state-of-thescience, EPA regulatory dispersion modeling application that includes the CALPUFF dispersion model (Scire et al. 2000a), the CALifornia METeorological (CALMET) diagnostic meteorological model (Scire et al. 2000b), and several supporting land-use and terrain preprocessing utilities. In short, meteorological observations provided to CALMET are used, in conjunction with land-use and terrain information, to create gridded fields of wind and boundary-layer parameters. These gridded fields are then supplied to the CALPUFF dispersion model, which, along with source configuration and emission information, calculates downwind plume concentrations.

DUSTRAN is seamlessly integrated within the Environmental System Research Institute's ArcMap GIS software (Version 9.x). As such, DUSTRAN functions as a console application within the ArcMap application and allows the user to interactively create a release scenario and run the underlying CALPUFF model and model components. All model components are dynamically linked and managed automatically by the DUSTRAN interface. Through the process of data layering within ArcMap, the model domain, sources, and results — including the calculated wind vector field and plume contours — can be displayed with other spatial and geophysical data sources to aid in analyzing and interpreting the scenario.

Further details on DUSTRAN and the dispersion models and processors that comprise it can be found in Allwine et al. (2006), Scire et al. (2000a), and Scire et al. (2000b). Readers unfamiliar with DUSTRAN who desire to conduct ecosystem studies similar to that described in this report are urged to consult the DUSTRAN User's Guide (Allwine et al. 2006) for detailed information on setting up and running DUSTRAN. 


\subsection{DUSTRAN Representation of Ft. Hood: Site Overview and Input Specifications}

A modeling domain encompassing the Ft. Hood military installation was selected, and GIS data layers were developed for use in DUSTRAN by Pacific Northwest National Laboratory (PNNL) staff. An installation CD containing all the necessary files, file settings, and data layers for performing simulations within DUSTRAN for the Ft. Hood site is available from the authors. Figure 3.1 displays the primary data layers within the Ft. Hood site. Data layers such as local water features, roadways, terrain elevations, site boundary, training areas, and bird habitats were provided by personnel at the Construction

Engineering Research Laboratory (CERL). Other data layers, such as geopolitical boundaries, are derived from publicly available databases. The DUSTRAN User's Guide contains detailed instructions on how to add a site to the DUSTRAN modeling system; readers interested in establishing a different modeling site are urged to consult this document.

As is shown in Figure 3.1, the Ft. Hood installation extends approximately $40 \mathrm{~km}$ in both the north-south and east-west directions. The local terrain generally slopes from west to east, with elevations ranging from a maximum of $394 \mathrm{~m}$ (red shading) to a minimum of $138 \mathrm{~m}$ (green shading) near Belton Lake. Primary endangered bird habitats that are of concern are shown in pale-yellow shading for the goldencheeked warbler and pale-gray shading for the black-capped vireo based on habitat information for these bird species compiled in 2003.

DUSTRAN simulations require the specification of several key inputs, including meteorological conditions and source-term characteristics. Meteorological inputs (Section 3.1) for the hypothetical simulation were defined using climatological values calculated from hourly observations for the surface station labeled "KGRK" in Figure 3.1. Fog-oil source term characteristics (Section 3.2) apply to example releases occurring within training areas (TAs) 8, 35, and/or 36. These areas are outlined in cyan in Figure 3.1 and have been identified by CERL and Ft. Hood personnel as the bounding source locations for FO training activities (personal communication from M. Hohmann to J. Rishel, November 2005). 


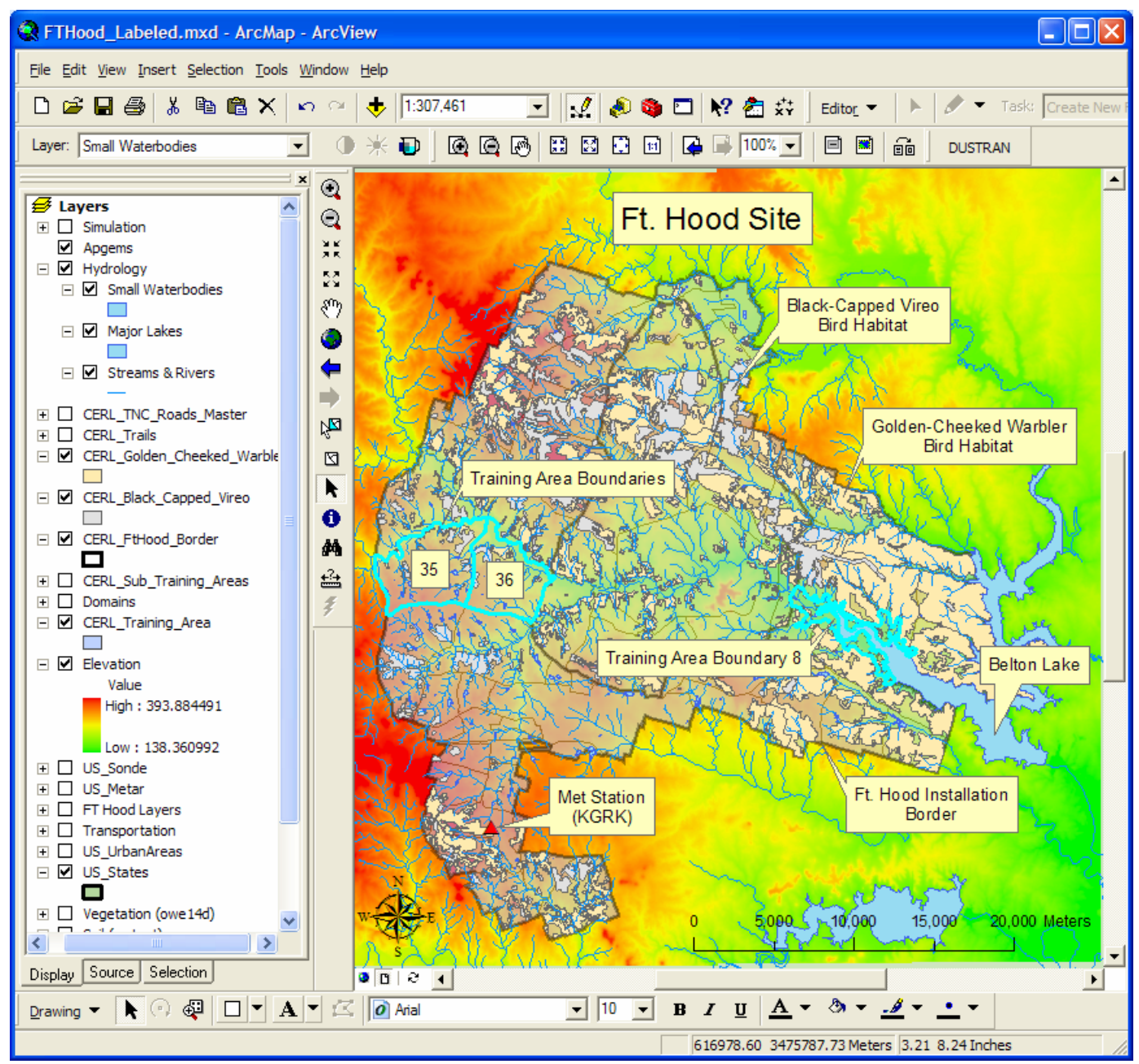

Figure 3.1. The Ft. Hood Site Within the DUSTRAN/ArcMap Interface with Various Layers Labeled, Including Boundaries for FO Training Areas (TA 8, 35, 36) and Specific Endangered Bird Habitats

\subsection{Meteorological Input Specification}

Accurate specification of meteorological conditions is important for quantifying plume transport and diffusion processes. CALMET, the diagnostic meteorological model in DUSTRAN, combines surface and upper-air meteorological observations in a physically consistent manner, accounting for localized effects from topography and land use, to create gridded fields of wind, temperature, and atmospheric stability. These gridded fields are used in the CALPUFF dispersion model to estimate downwind plume concentrations.

Meteorological observations can be supplied to DUSTRAN using a variety of methods, the simplest of which is called the "Single Observation" method. As the name implies, the "Single Observation" method only requires the specification of a single set of surface conditions-namely wind speed, wind direction, temperature, and atmospheric stability. Gridded fields are calculated in CALMET by adjusting the single observation for local terrain effects and mass consistency throughout the domain. Subsequent temporal 
changes of the meteorological grid are based on persistence of the initial conditions, with modifications accounting for the time evolution of the atmospheric boundary layer.

In this report, “Single Observation” meteorological data have been developed for Ft. Hood by calculating climatological values from hourly data provided by CERL personnel to PNNL staff for the Robert Gray (KGRK) automated surface observation station (ASOS). The meteorological station, shown in Figure 3.1, is located within $20 \mathrm{~km}$ of nearby FO release exercise training areas (TA 8, 35, and 36). Table 3.1 provides additional information about this meteorological station.

Table 3.1. Location Information for ASOS Site Providing Hourly Meteorological Data

\begin{tabular}{|l|l||}
\hline \multicolumn{1}{|c|}{ Parameter } & \multicolumn{1}{c|}{ Identifier } \\
\hline ICAO $^{(\mathrm{a})}$ Location Indicator & KGRK \\
\hline Station Name & Fort Hood, Robert Gray AAF \\
\hline State & TX \\
\hline $\mathrm{WMO}^{(\mathrm{b})}$ Region & 4 \\
\hline Station Position & $31.07^{\circ} \mathrm{N}, 97.82^{\circ} \mathrm{W}$ \\
\hline Station Elevation & 309 Meters \\
\hline $\begin{array}{l}\text { (a) ICAO }=\text { International Civil Aviation Organization } \\
\text { (b) WMO = World Meteorological Organization }\end{array}$ \\
\hline
\end{tabular}

Climatological values of wind speed and wind direction were determined and are presented as windroses in Appendix A for April through August - the primary residency period of the endangered goldenchecked warbler and black-capped vireo on the Ft. Hood installation. The windroses are constructed using the five most complete sequential years (1995-1999) of hourly meteorological data for KGRK and are valid for the morning hours of 0500 to 1100 local standard time (LST), the likely time period for typical FO training exercises on the Ft. Hood installation (personal communication, M. Hohmann to J. Rishel, November 2005).

As is illustrated by the windroses in Appendix A, the most frequent wind direction is from the south $\left(180^{\circ}\right)$ at speeds generally ranging from 2.1 to $8.8 \mathrm{~m} / \mathrm{s}$. Slower wind speeds ( 2.1 to $3.6 \mathrm{~m} / \mathrm{s}$ ) occur most often, as would be expected because of increased early-morning stability. Table 3.2 summarizes values representing typical meteorological conditions that might be observed during an early-morning training exercise at Ft. Hood. These values are used to initialize single-observation meteorological inputs for the example DUSTRAN simulation of a hypothetical FO release presented in Section 4.0.

The DUSTRAN User's Guide contains detailed instructions on how to use actual observations from multiple meteorological stations, including NOAA archived data, in DUSTRAN simulations. Hourly sequential surface meteorological data should be considered for use in detailed investigations of actual past FO releases. 
Table 3.2. Sample “Single Observation” Meteorological Data Used in a Hypothetical DUSTRAN Simulation

\begin{tabular}{||l|l|}
\hline Single-Observation Parameter & \multicolumn{1}{|c|}{ Value } \\
\hline Wind Direction & $180^{\circ}$ \\
\hline Wind Speed & $2.5 \mathrm{~m} / \mathrm{s}$ \\
\hline Temperature & $65^{\circ} \mathrm{F}$ \\
\hline Stability & $\mathrm{F}-$ Moderately Stable \\
\hline Mixing Height & $500 \mathrm{~m}$ \\
\hline Relative Humidity & $50 \%$ \\
\hline Ambient Pressure & $1000 \mathrm{mb}$ \\
\hline
\end{tabular}

\subsection{Source-Term Input Specification}

Source-term information for FO releases at Ft. Hood were developed using three primary sources: (1) previous S\&O studies (ERDC/CERL 2001; Policastro and Dunn 1985; Katz et al. 1980; Liss-Suter 1978; Liljegren et al. 1988), (2) information about FO use at Ft. Hood provided by CERL personnel to PNNL staff (personal communication, M. Hohmann to J. Rishel, November 2005), and (3) publicly available Title $\mathrm{V}$ permits issued at Ft. Carson, Colorado (http://www.cdphe.state.co.us/ap/downop/ep110p04.pdf). Data from previous S\&O studies indicate that $99 \%$ of the particles produced from FO releases are less than 10 microns in size, with measurements made by Policastro and Dunn (1985) indicating a binned size distribution within the 0.3- to under 3.0-micron range. These references also indicate that typical fog generators use about 1 gallon of oil per minute, while Title V permits indicate that most generators are at least $99 \%$ efficient in converting the oil to droplets. Furthermore, information provided by CERL personnel to PNNL staff, based on answers to questions posed to a chemical smoke commander at Ft. Hood, indicate that primary FO TAs at Ft. Hood include TAs 8, 35, and 36 (personal communication, M. Hohmann to J. Rishel, November, 2005). These areas are outlined in cyan in Figure 3.1. Within the bounding TAs, FO is released from a moving vehicle that generally covers a $0.5 \mathrm{~km}^{2}$ area during a 3- to 6-hour training exercise. Mornings are preferred times for conducting military training exercises involving FO releases because increased atmospheric stability increases FO effectiveness as an obscurant by minimizing plume dilution and potential ground liftoff.

Table 3.3 summarizes the above source-term characteristics, which are used to initialize a hypothetical FO area source release in DUSTRAN (see Section 4.0). The source information represents likely FO release characteristics expected during a routine training exercise at Ft. Hood.

The DUSTRAN User's Guide contains detailed instructions on how to input source-term information (point, line and area) into DUSTRAN. Actual release information should be considered for use in detailed investigations of past FO releases. 
Table 3.3. Sample FO Source-Term Characteristics for Use in DUSTRAN

\begin{tabular}{||l|l||}
\hline \multicolumn{1}{||c||}{ Source Characteristic } & \multicolumn{1}{c||}{ Value Selected } \\
\hline Release Points & $0.5 \mathrm{~km}^{2}$ areas within TAs 8, 35, and/or 36 \\
\hline Release Height & $2 \mathrm{~m}$ above ground level \\
\hline Release Start Time & $0700 \mathrm{LST}$ \\
\hline Release Duration & 3 hours \\
\hline Particle Generation Rate & 57 grams/second \\
\hline Generated Particle Diameters & 2.5 microns or less \\
\hline
\end{tabular}




\subsection{Sample Fog-Oil Release Simulation at Ft. Hood}

Using the representative meteorological conditions and source-term characteristics developed in Sections 3.1 and 3.2, respectively, a hypothetical FO release can be simulated in DUSTRAN. Model inputs for this hypothetical FO release have been saved and included as a scenario with the Ft. Hood site, thereby allowing the simulation to be easily reproduced. Detailed instructions for creating different model scenarios-from entering meteorological data to creating sources in the map window to running the model—are provided in the DUSTRAN User's Guide. Readers unfamiliar with DUSTRAN are urged to consult Allwine et al. (2006) and to run the hypothetical release presented in this section before setting up additional scenarios.

The simulation presented in this section represents a hypothetical FO release under typical conditions. The release involves a 3-hour FO training exercise conducted within TA 36 and begins at 0700 LST on April 25, 2005. The FO generator has a release rate of $57 \mathrm{~g} / \mathrm{s}$ and is mounted to a military vehicle that traverses an area of approximately $0.5 \mathrm{~km}^{2}$ (Table 3.3). Mean winds observed at KGRK are from the south $\left(180^{\circ}\right)$ at $2.5 \mathrm{~m} / \mathrm{s}$, and atmospheric stability is moderately stable (Table 3.2).

\subsection{Calculated Wind Field}

A sample 10-meter-above-ground wind field at 0700 LST on April 25, 2005, is displayed in Figure 4.1. The model domain is $50 \mathrm{~km}$ in the north-south and east-west directions and is shown as the dashed box surrounding the Ft. Hood installation. The model resolution (i.e., locations where model calculations are performed) is $1 \mathrm{~km}$, although for image clarity, only every-other wind vector is plotted. As is shown in Figure 4.1, winds are generally from the south; however, there is evidence of some local channeling of the winds in the lower lying terrain due to the increased early-morning stability. Figure 4.2, a zoomed-in view of the region in and around TA 36, clearly shows that local winds are indeed channeled to the northwest. 


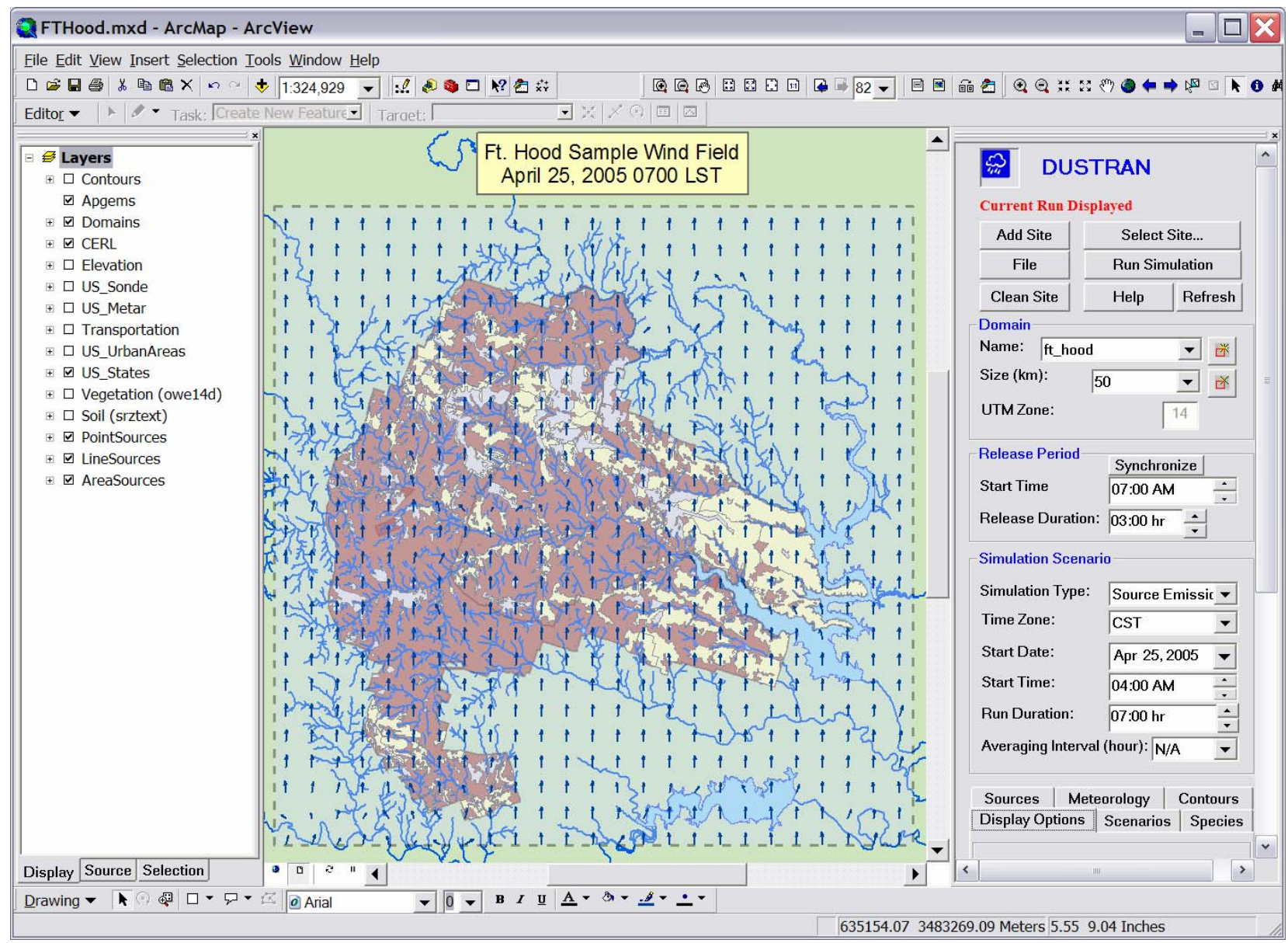

Figure 4.1. 0700 LST Wind Field at 10 Meters Above Ground Level (AGL) for Sample April 25, 2005, FO Simulation at Ft. Hood 


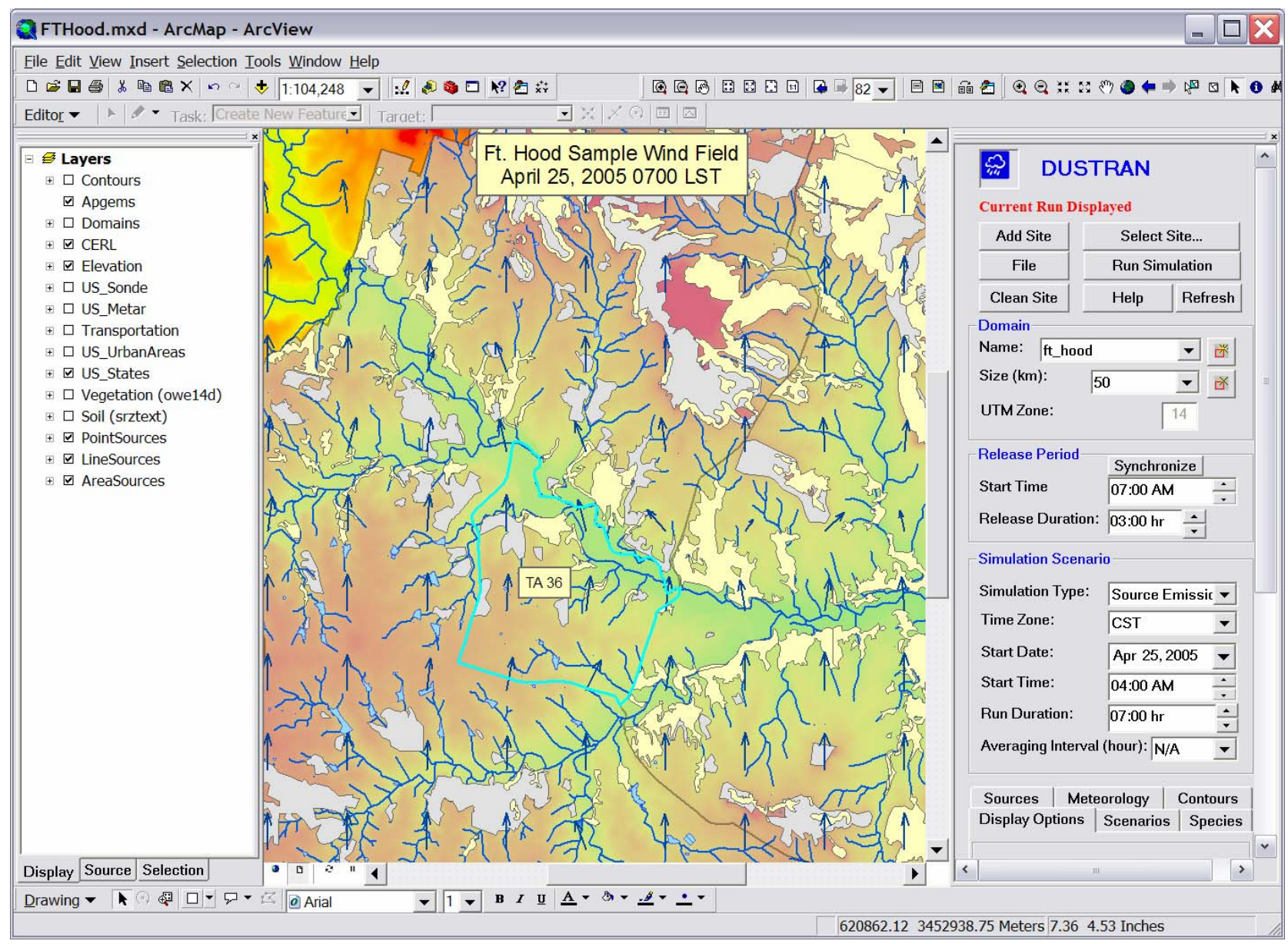

Figure 4.2. Zoomed-in View of the 0700 LST Wind Field Near TA 36

\subsection{Calculated Concentrations}

Figure 4.3 shows sample 1-hour average (0800-0900 LST) FO concentration contours. Concentrations spanning four orders of magnitude, from $0.0001 \mathrm{mg} / \mathrm{m}^{3}$ (green) to a maximum of $1.0 \mathrm{mg} / \mathrm{m}^{3}$ (red), are displayed and labeled in the figure. One-hour average concentrations for other time periods (not shown) reveal similar concentration ranges and have a maximum magnitude on the order of $1.0 \mathrm{mg} / \mathrm{m}^{3}$.

Downwind extents for each concentration contour vary from hour-to-hour because of plume transport and diffusion; however, the maximum downwind extent of the $1.0 \mathrm{mg} / \mathrm{m}^{3}$ contour never exceeds $0.5 \mathrm{~km}$ from the source for this hypothetical simulation.

Project biologists have derived empirical FO toxicological response functions for certain insect types that are important food sources for the endangered golden-cheeked warbler and black-capped vireo avian species. Insects (and/or their life-stages) were exposed to FO in controlled wind-tunnel experiments at well-defined concentrations and time periods (personal communication, C. Driver to J. Rishel, July 2006). Results from the experiments indicate that toxicological effects, if any, occur when FO concentrations are in excess of $100 \mathrm{mg} / \mathrm{m}^{3}$ — at least two orders of magnitude higher than DUSTRAN-predicted concentrations. Given that DUSTRAN-simulated FO concentrations are well below this threshold for 
each simulated time-step, toxicological effects are anticipated to be highly localized and occur very near the source.

To further investigate this finding, plume centerline concentrations were calculated using a traditional Gaussian plume model (Turner 1994) for a ground-level point-source release. Results are plotted in Figure 4.4 for a range of stability classes—B (moderately unstable) through E (moderately stable) — with the latter stability class closely representing conditions used within the hypothetical DUSTRAN simulation. Concentrations plotted in Figure 4.4 were calculated using meteorological and source-term parameters that were comparable to those used in DUSTRAN, namely, a wind speed of $2.5 \mathrm{~m} / \mathrm{s}$ and an emission rate of $57 \mathrm{~g} / \mathrm{s}$. In this case, the $57 \mathrm{~g} / \mathrm{s}$ emission rate provides a conservative estimate of downwind concentrations since emissions are assumed to be non-depositing and are coming from a stationary point source (i.e., emissions are not being released over a broad area from a moving vehicle).

Figure 4.4 shows that concentrations decrease rapidly from the source, with average concentrations falling below $100 \mathrm{mg} / \mathrm{m}^{3}$ at downwind distances of 60,175 , and 390 meters for stability classes $\mathrm{C}$, D, and E, respectively. Concentrations for stability class B fall below $100 \mathrm{mg} / \mathrm{m}^{3}$, well within 50 meters of the source. Given this analysis, toxicological impacts from FO releases with comparable source characteristics and meteorological conditions are conservatively expected to occur within 400 meters of the source, bounding an area approximately $0.5 \mathrm{~km}^{2}$ centered on the source. 


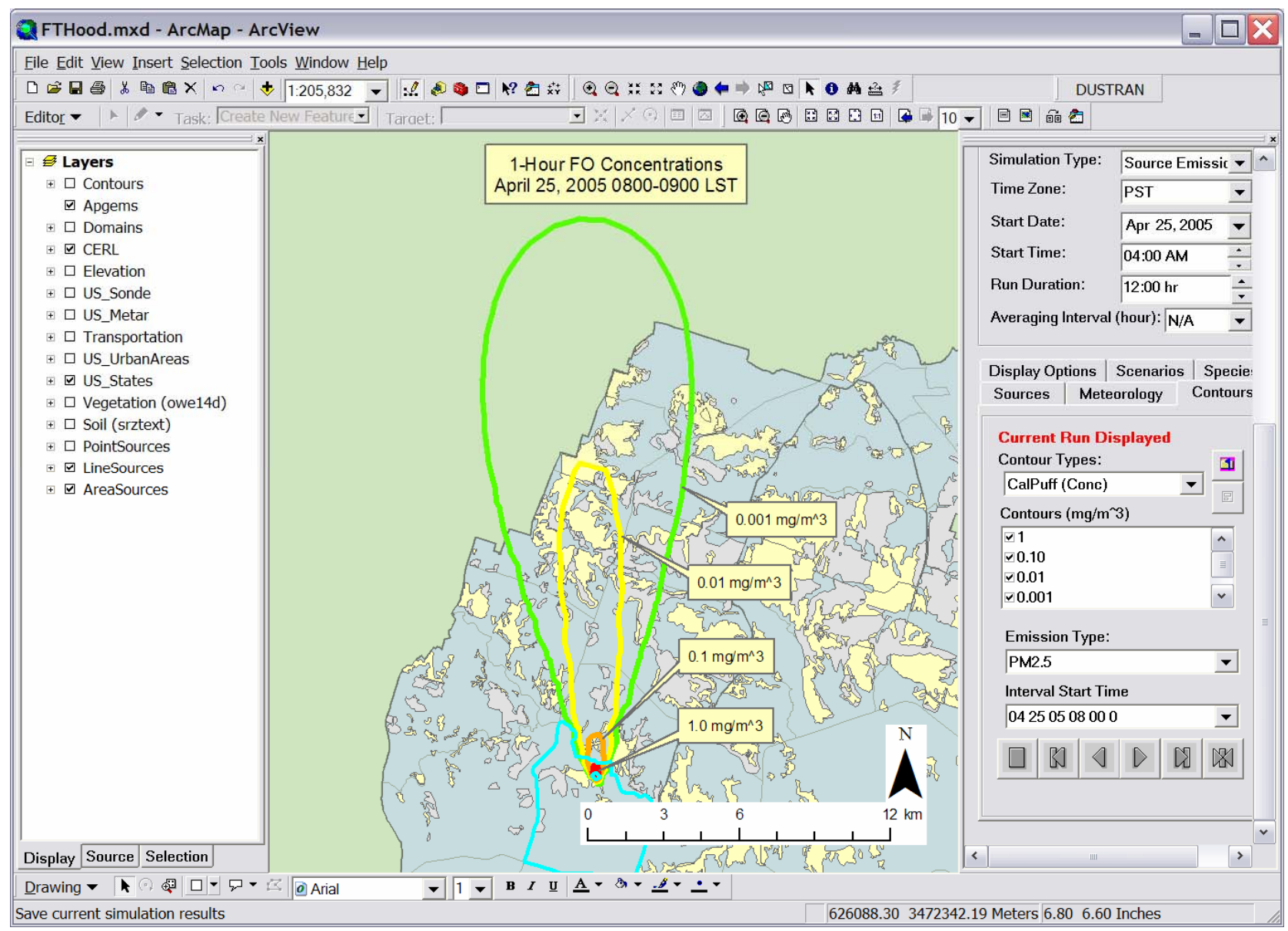

Figure 4.3. One-hour (0800-0900 LST) Average Concentrations from a Hypothetical FO Release Within Training Area 36. Four orders of magnitude are displayed, with a maximum concentration of $1 \mathrm{mg} / \mathrm{m}^{3}$ (red contour) occurring within 50 meters of the source. 
Concentration $\left(\mathrm{mg} / \mathrm{m}^{3}\right)$ vs. Downwind Distance $(\mathrm{m})$

For Pasquill Guifford Stability Classes B-E

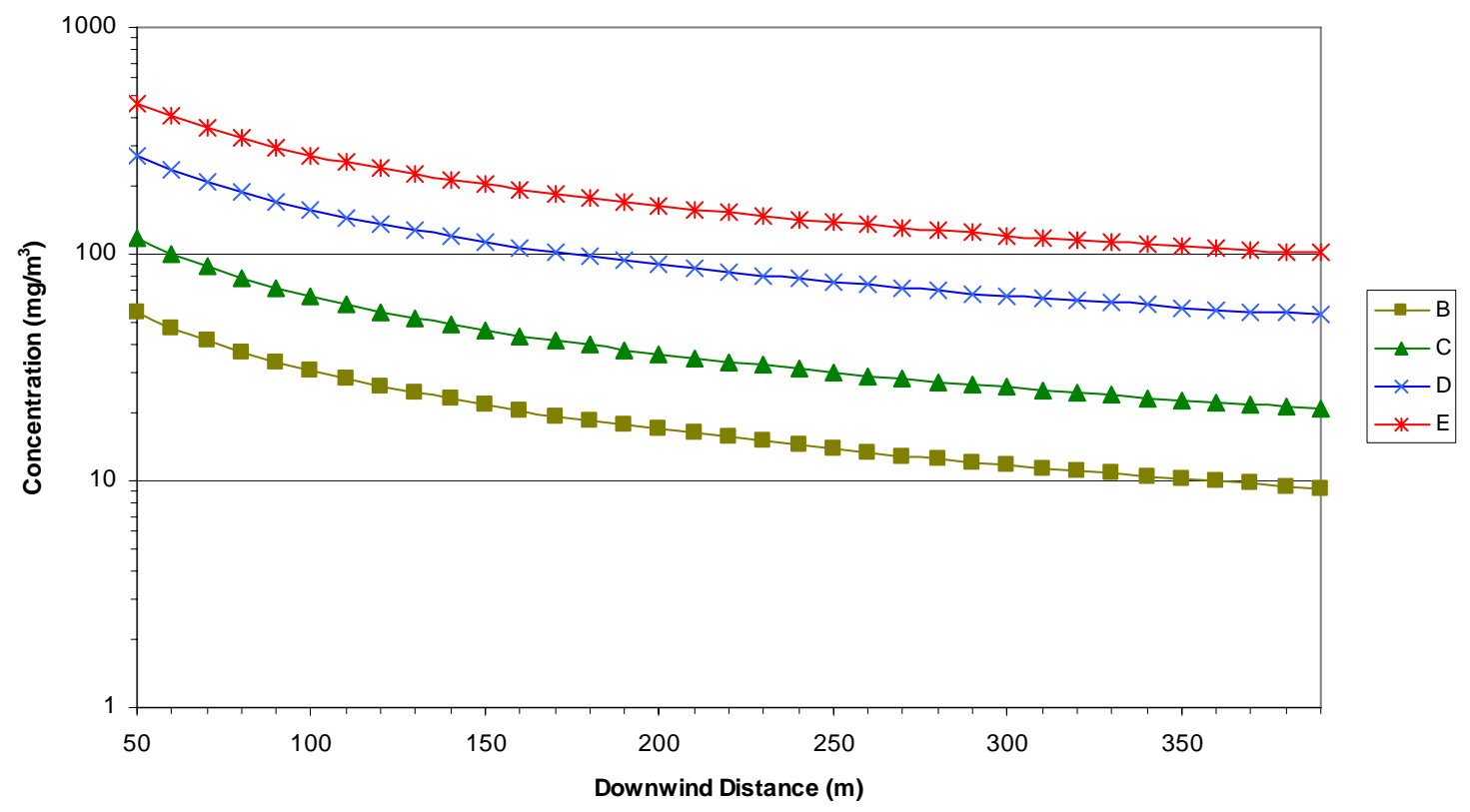

Figure 4.4. Average Concentrations Predicted from Straight-Line Gaussian Plume Model (Turner 1994) for a Ground-Level Release Using a Wind Speed of $2.5 \mathrm{~m} / \mathrm{s}$ and a Source Emission Rate of $57 \mathrm{~g} / \mathrm{s}$. Concentrations decrease rapidly from the source and drop below $100 \mathrm{mg} / \mathrm{m}^{3}$ at a maximum downwind distance of 390 meters from the source for all stability classes. 


\subsection{Advanced Analysis Topics}

This section presents advanced analysis topics that can be employed by users of the DUSTRAN modeling system. Topics addressed in this section are geared toward analysts and users alike who are using DUSTRAN to investigate ecological impacts, such as the effects of FO releases on insect populations at Ft. Hood. Specific topics covered in this section include adjusting contour levels to user-defined values, modifying contour colors after a model simulation, and creating insect population polygons (i.e., areas) for display and use within the DUSTRAN modeling system. Appendix B presents a sample procedure using native ArcMap functionality to calculate the area shared between an insect-population polygon and a DUSTRAN-predicted concentration contour.

\subsection{Adjusting Contour Levels}

The DUSTRAN modeling system displays contours of simulation results to reveal the nature and character of the released plume. The displayed contours typically cover several orders of magnitude. A user may want to adjust the contour levels to reveal specific concentration levels of interest, such as FO concentrations that cause a lethal dose (LD) to a specific insect type.

Contour levels and the units in which they are displayed can be adjusted within a parameter file called Cal.par. The Cal.par file is found within the Static directory of the model site (e.g., C:IDUSTRAN\FT_Hood $\backslash$ StaticData) and is used by the DUSTRAN modeling system to set several site-specific, high-level operational parameters. The exact format specification of the Cal.par file is presented in detail in the DUSTRAN User's Guide. Of particular relevance to this discussion are lines 82-87, which affect contour units and the number of contour levels that are displayed. Figure 5.1 displays an excerpt from the Cal.par file for the Ft. Hood site. Lines that affect contour plotting within the current configuration are labeled with numbers in parenthesis ( ) and are for identification purposes only; line numbers are not actually used in the Cal.par file. The Cal.par file can be opened and edited using any standard word processing program.

Lines 82-85 within the Cal.par file are used to set display units for concentration, deposition, exposure, and total deposition contours within the DUSTRAN interface. Mass units from the CALPUFF dispersion model are always output in grams (g). Therefore, conversion factors must be supplied if other output units are to be displayed within DUSTRAN. For the Ft. Hood site, mass output units are set to be displayed in milligrams (mg); therefore, the conversion factor is $1.0 \mathrm{E}+3$. If the user wants output to be displayed in mass units other than milligrams, the appropriate conversion factor from grams ( $\mathrm{g}$ ) to the desired unit should be entered.

Line 86 sets the minimum contour level to be used by DUSTRAN's contouring module. As indicated by the comment at the end of this line (see Figure 5.1), it is recommended that the minimum contour level be set at 3 orders of magnitude smaller than the smallest specified contour level (i.e., the value that will be entered on line 88).

Line 87 is used to set the number of contour levels to be displayed by the DUSTRAN modeling system. Subsequent lines in the Cal.par file are used to define the exact contour levels. For example, 10 contour levels are currently displayed for the Ft. Hood site. The values for each contour level immediately follow 
(lines 88 through 97) and are based on orders of magnitude, starting with 1.0E-7 and increasing to $1.0 \mathrm{E}+3$. These values can be edited to represent specific contour levels, such as values representing a lethal dose to a specific insect type.

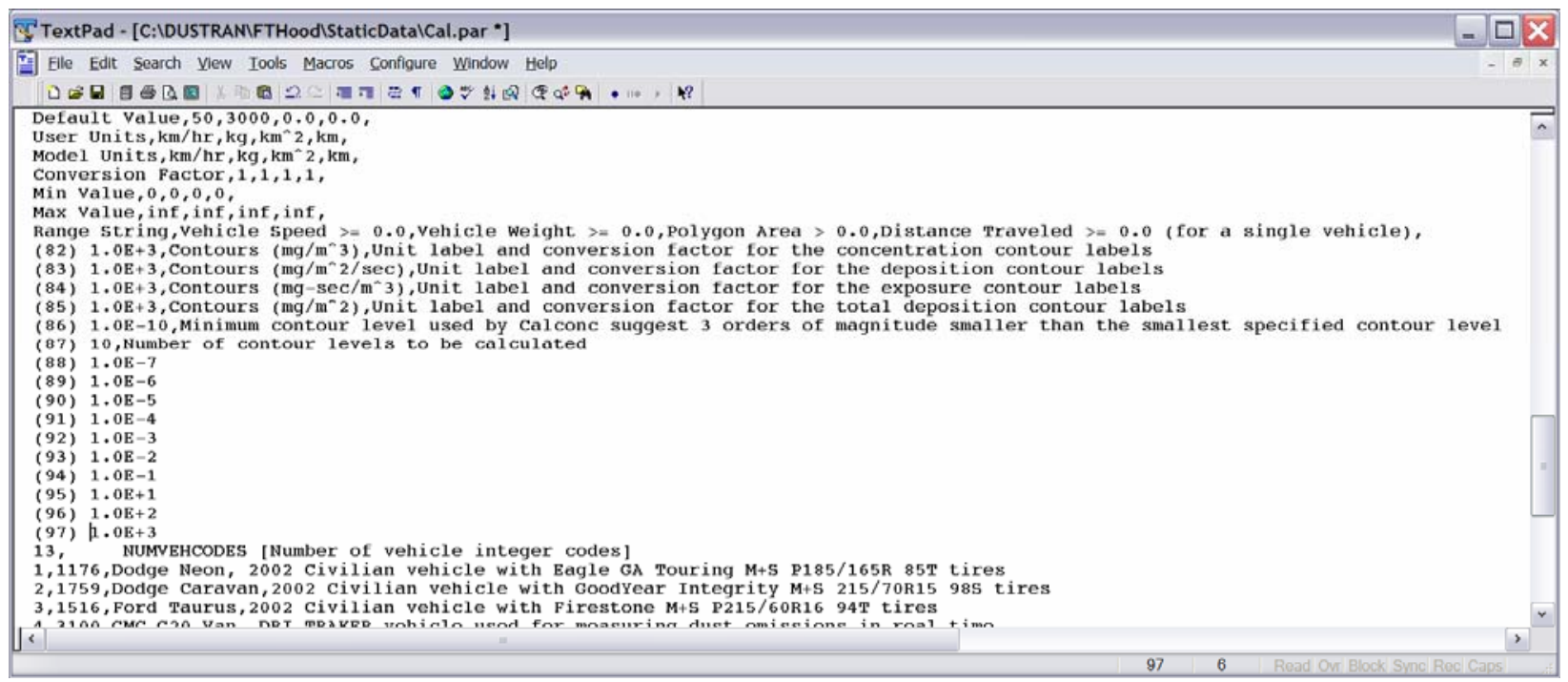

Figure 5.1. The Cal.par File for the Ft. Hood Site. Lines 82 through 97 (labeled within parentheses) are used to adjust contour units and levels displayed by the DUSTRAN modeling system.

\subsection{Changing Contour Display Colors}

As is detailed in the DUSTRAN User's Guide, the "Contours" checkbox on the "Display Options" tab can be selected after performing a simulation to display model-calculated contours in the map window. By default, all contour levels are displayed in red. The user has the option of adjusting colors for specific contour levels by using the "Layout View" within ArcMap. Layout View allows for modifying specific elements within the map window and is generally used for adjusting elements before saving or printing the display.

To adjust contour colors after performing a DUSTRAN model simulation, select "Layout View" from the ArcMap "View" menu. Each contour is a separate element within the layout view; properties for each element can be adjusted by double-clicking on the contour. Figure 5.2 is the "Contour Properties" window for a specific contour level and allows for the color, width, and line symbology (e.g., solid or dashed) to be modified. A range of colors and symbologies can be used to delineate between specific contour levels of interest. 


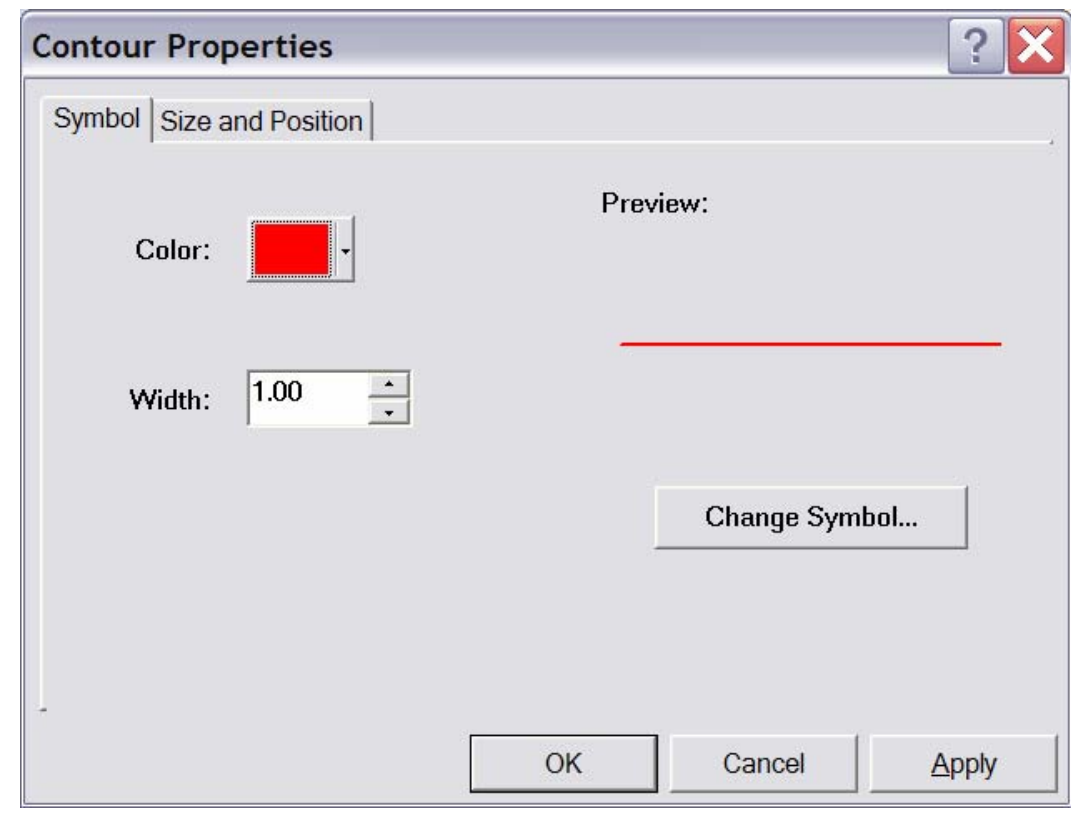

Figure 5.2. The “Contour Properties” Window for each Contour Level can be Adjusted for Color and Width by Selecting the Contour Level Within "Layout View" in ArcMap

\subsection{Using the Polygon Layer Creator Tool to Create Insect Populations}

The "Polygon Layer Creator" is a stand-alone software utility that has been developed as part of the Ft. Hood project effort. The application is used to create polygon-based GIS data and is ideal for creating layers that can be displayed and interrogated within the ArcMap system. In the context of the current discussion, the Layer Creator utility can be used to create polygons that represent certain insect types or insect population areas; the polygons can then be queried against DUSTRAN-generated concentration contours, for example, to calculate the affected area from a given FO plume release (see Appendix B).

This section provides an overview of the Layer Creator utility, with general instructions for creating, saving, and importing insect populations into the DUSTRAN modeling system. The DUSTRAN User's Guide fully documents the use of the Polygon Layer Creator utility in detail.

\subsubsection{Starting the Polygon Layer Creator}

The Polygon Layer Creator is a separate application and runs independently from the DUSTRAN modeling system. It can be accessed by double-clicking on the file called "CreateLayer.exe" within the main DUSTRAN directory. Once started, the application's interface will be displayed with all buttons disabled except for the "Load MXD file” $\square$ button. The site .mxd file must be loaded before creating or editing site-specific polygons within the Layer Creator utility.

\subsubsection{Loading a Site's .MXD File}

An .mxd file contains layers that describe a DUSTRAN site and is used to display the site within ArcMap. An .mxd file has been created for the Ft. Hood site and is available within the root directory for 
the site (e.g., C:IDUSTRAN $\left.\backslash F t \_H o o d \backslash F t H o o d . m x d\right)$. The .mxd file must be loaded before creating or editing site-specific polygons. To load a site's .mxd file:

- Click on the "Load MXD file” $\square$ button.

- Using the browse window, navigate to the DUSTRAN site directory for Ft. Hood and select the .mxd file for that site.

- Click on the "Open" button of the browse window to open the .mxd file and close the browse window.

- $\quad$ Once the .mxd file has been selected, the map layers for the selected site will be loaded automatically into the map display, and the layer names will be displayed in the "Layers" list (Figure 5.3).

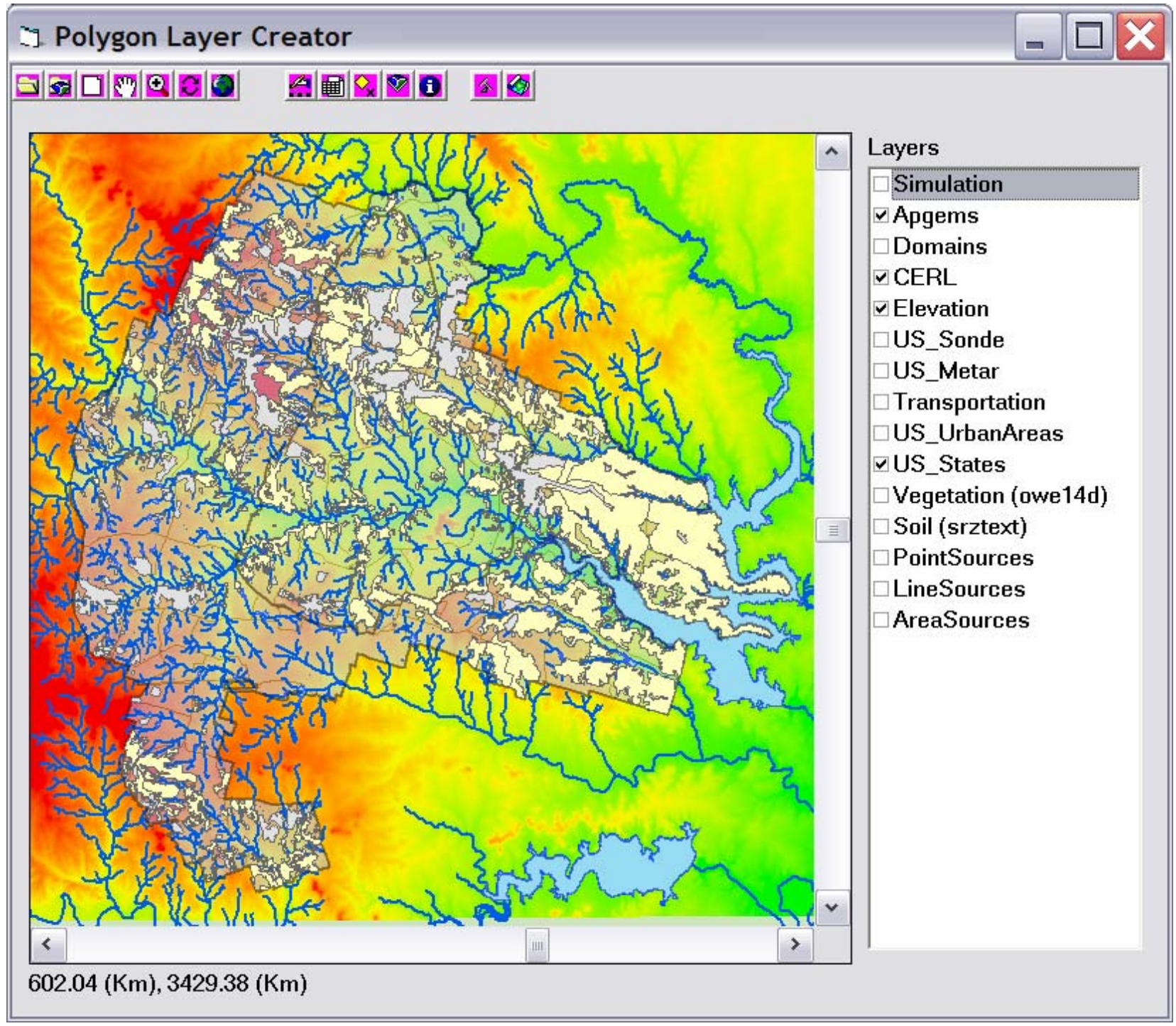

Figure 5.3. Ft. Hood .mxd File Loaded into the Polygon Layer Creator Utility 


\subsubsection{Adding Polygons to the Layer}

The "Polygon Layer Creator" allows for the creation of polygon areas that spatially represent certain characteristics or features, such as insect types or insect populations. Each polygon is assigned a value, called a grid code, that identifies it from surrounding polygons. For example, a specific insect type may be assigned a grid code ID that identifies it from other insect types, or, for a given insect type, the grid code ID may represent a population count. These grid codes can be interrogated using ArcMap spatial query tools after performing a DUSTRAN simulation to quantify toxicological impacts. This section provides guidance on how to create polygon shapes within the Layer Creator utility. Detailed instructions on other operations that can be performed within Layer Creator, such as editing, deleting, or modifying polygon boundaries, are discussed in the DUSTRAN User's Guide. Appendix B outlines a procedure for querying the polygons against DUSTRAN-generated concentration contours to calculate, for example, the extent of an insect population area potentially affected by a given FO plume release.

Polygons can be manually drawn and added to a layer to create a collection, or set of polygons. Polygons are differentiated by their grid code, which is a value that is entered after drawing the polygon shape. To add a new polygon to a polygon set:

- Click on the “Add polygons" $\mathbf{a}$ button.

- Draw the new polygon onto the map display using the mouse. Each corner of the polygon is created by a left-click of the mouse at the desired location.

- When finished drawing the desired polygon, double-click on the last point of the polygon. An input window will be displayed asking for the Grid Code value associated with the polygon (Figure 5.4); this code can be used to identify a particular insect type or insect population count.

- Enter the value into the input window and click on the "OK” button.

- The new polygon will then be added to the map display. Figure 5.5 is a sample display of several polygons that have been added to the Ft. Hood site and can be used to represent populations of specific insect types.

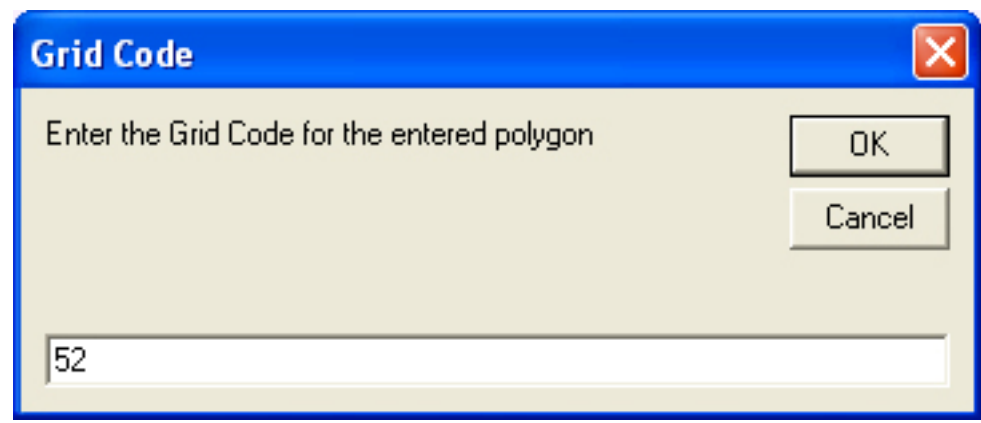

Figure 5.4. Grid Code Input Window for Specifying Numbers that Represent Specific Insect Types or Populations 


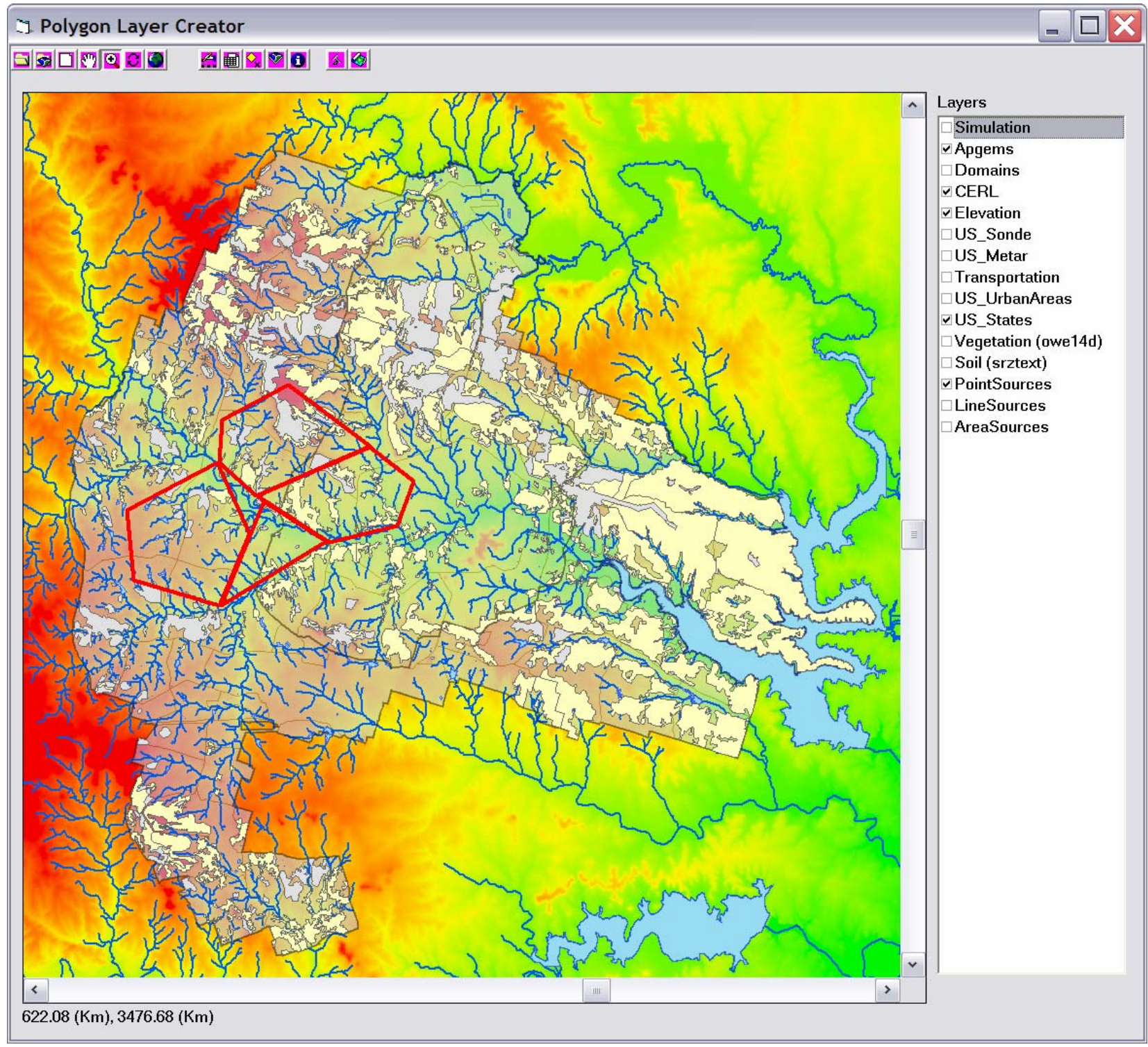

Figure 5.5. A Series of Polygons Created Within the Layer Creator Utility; each Polygon Represents an Insect Population Count

\subsubsection{Saving the Output Shape File}

The polygons created in Layer Creator can be saved to a shape file for display and further use in the DUSTRAN modeling system. The shape files, along with DUSTRAN concentration contours, can be interrogated using ArcMap spatial query tools to estimate impacted areas in and around the Ft. Hood installation. To create and save the shape files, click on the "Create shape file" button; a file browse window will be displayed. Enter a name for the output files and then click on the "Open” button to save the files. The saved shape files are then available upon loading the site within the DUSTRAN modeling system. 


\subsection{References}

Allwine, KJ, FC Rutz, WJ Shaw, JP Rishel, BG Fritz, EG Chapman, BL Hoopes, and TE Seiple. 2006. DUSTRAN 1.0 User's Guide: A GIS-Based Atmospheric Dust Dispersion Modeling System. PNNL-16055, Pacific Northwest National Laboratory, Richland, WA.

Allwine, KJ, FC Rutz, WJ Shaw, BG Fritz, and BL Hoopes. 2004. Third Annual Progress Report: Development of a GIS-Based Complex Terrain Model for Atmospheric Dust Dispersion. PNNL-14555, Pacific Northwest National Laboratory, Richland, WA.

Engineer Research and Development Center/Construction Engineering Research Laboratory (ERDC/CERL). 2001. Non-facility Particulate Matter Issues in the Army-A Comprehensive Review. ERCD-CERL, Champaign, IL.

Katz S, A Snelson, R Butler, R Farlow, and R Welker. 1980. Data from Physical and Chemical Characterization of Military Smokes II: Fog Oils and Oil Fogs. IIT Research Institute, Chicago, IL.

Liljegren JC, WE Dunn, GE DeVaull, and AJ Policastro. 1988. Field Measurement and Model Evaluation Program for Assessment of the Environmental Effects of Military Smokes: Field Study of Fog Oil Smokes. A205 344, Argonne National Laboratory, Argonne, IL.

Liss-Suter D. 1978. Literature Review - Problem Definition Studies on Selected Toxic Chemicals. Volume 8. Environmental Aspects of Diesel Fuel and Fog Oils SGF Number 1 and SGF Number 2 and Smoke Screens Generated from Them. Franklin Institute Research Laboratories, Philadelphia, PA.

Policastro AJ, and WE Dunn. 1985. Survey and Evaluation of Field Data Suitable for Smoke Hazard Model Evaluation. ANL/ER-85-3, AD-A161 880, U.S. Army Medial Bioengineering Research and Development Laboratory, Fort Detrick, Frederick, MD.

Scire JS, DG Strimaitis, and RJ Yamartino. 2000a. A User's Guide for the CALPUFF Dispersion Model (Version 5). Earth Tech, Inc., Concord, MA.

Scire JS, FR Robe, ME Fernau, and RJ Yamartino. 2000b. A User's Guide for the CALMET Meteorological Model (Version 5). Earth Tech, Inc., Concord, MA.

Turner BC. 1994. Workbook of Atmospheric Dispersion Estimates: An Introduction to Dispersion Modeling. $2^{\text {nd }}$ Edition, Lewis Publishing, Boca Raton, FL. 

Appendix A

Windrose Plots 


\section{Appendix A-Windrose Plots}

Meteorological data from the Robert Gray (KGRK) automated surface observation station, located near Ft. Hood training areas (see Section 3.1), was provided to PNNL staff by CERL (personal communication, M. Hohmann to J. Rishel, November 2005). Data from this site for April through August (and in general) were found to be the most complete for 1995-1999. Therefore, the meteorological data set for these years for the hours 0500 to 1100 LST for April through August was analyzed in depth. As noted in Section 3.1, FO releases are expected to occur in the early morning hours while April through August is the temporal period during which the endangered golden-cheeked warbler and black-capped vireo reside at Ft. Hood. The following windrose plots summarize the results of the climatological analysis. 


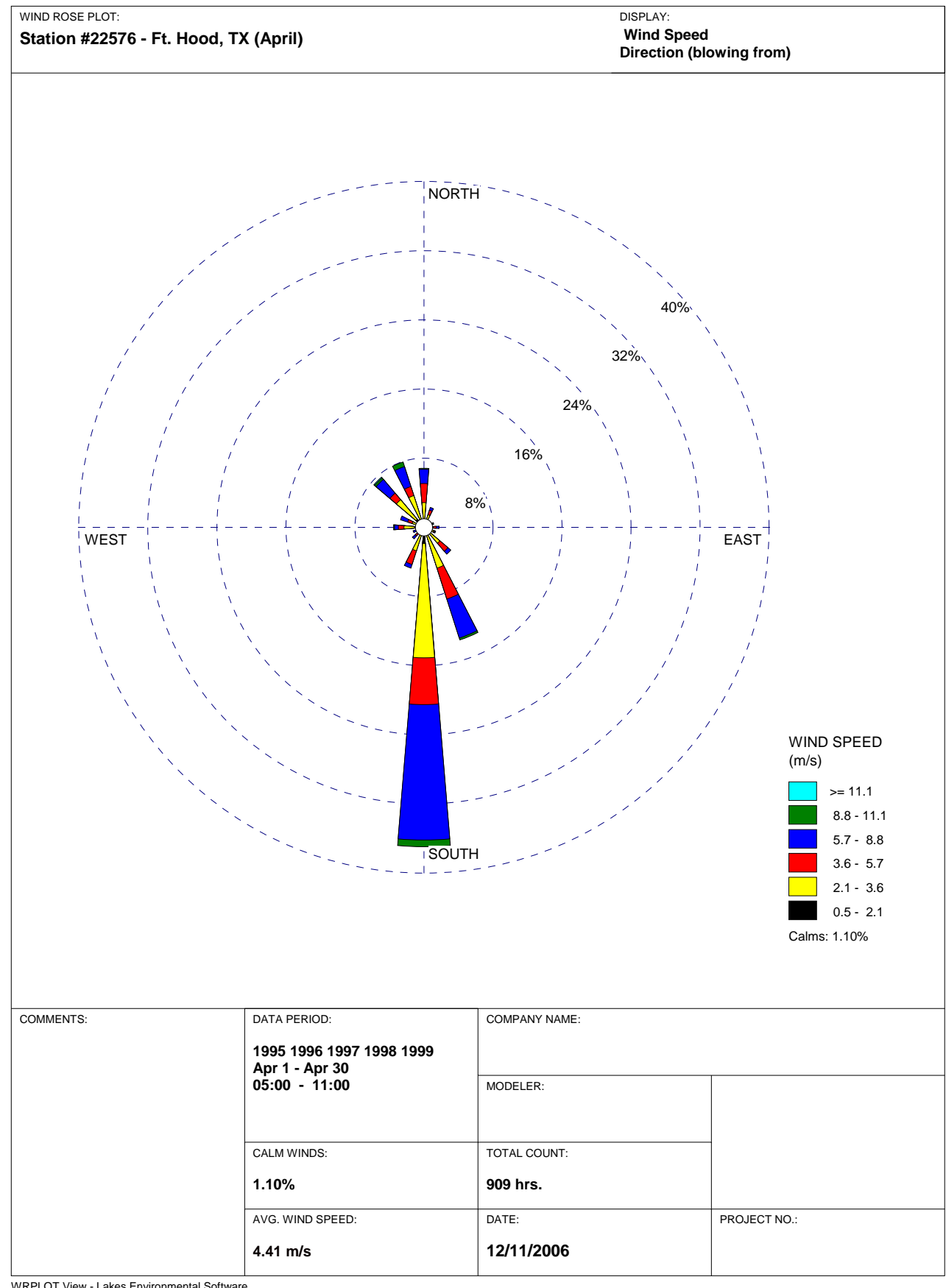

A. 2 


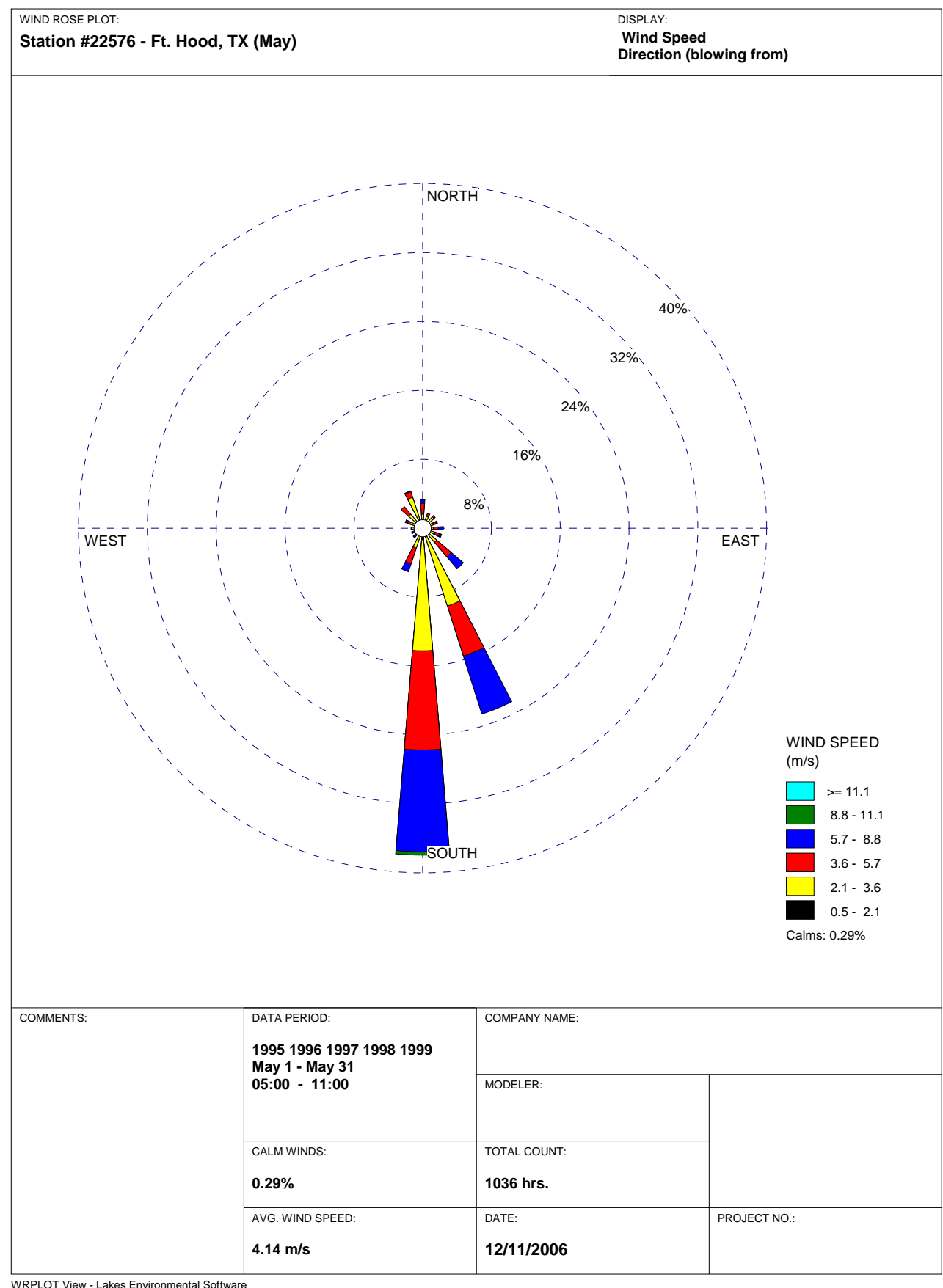

A.3 


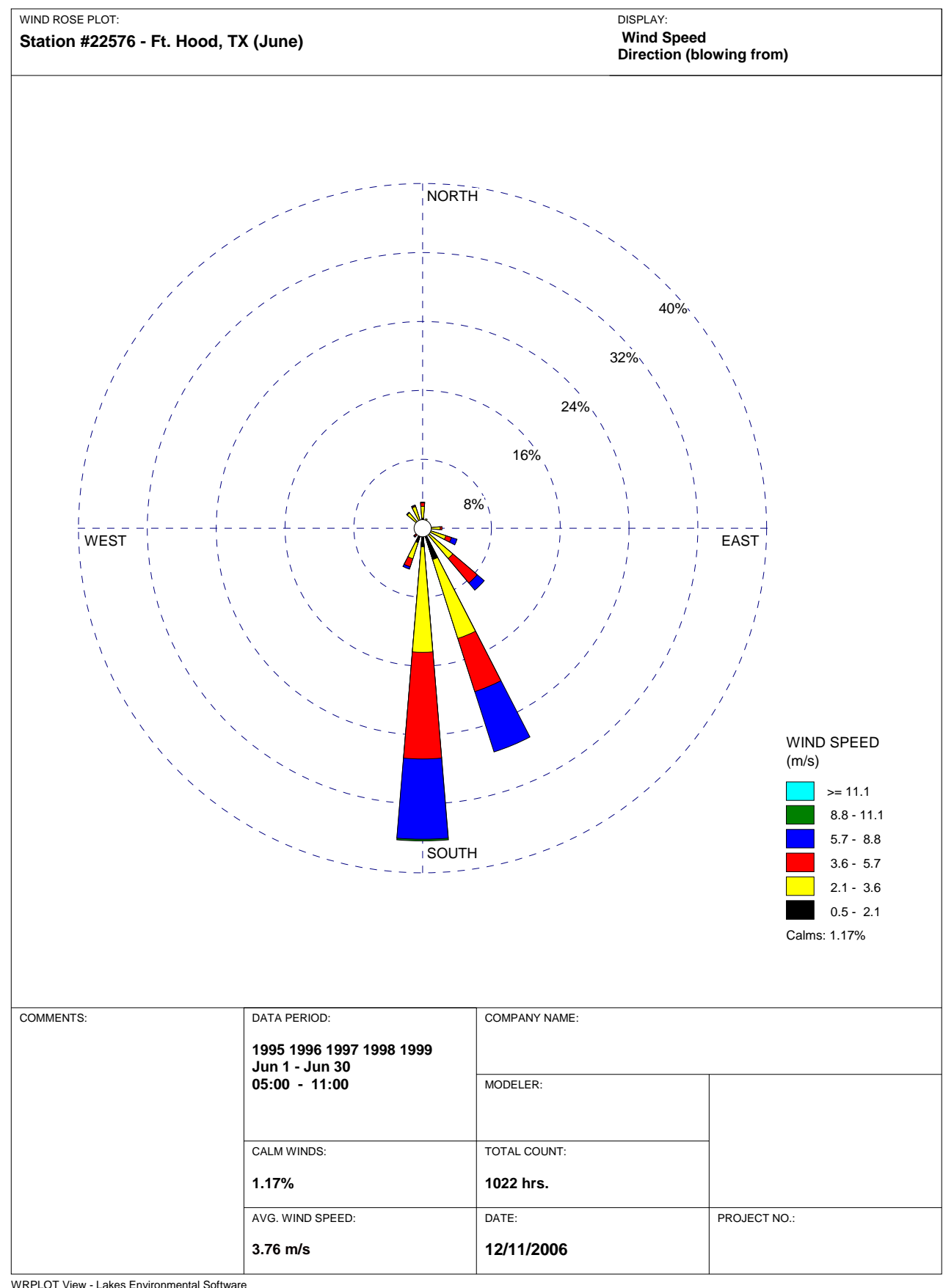




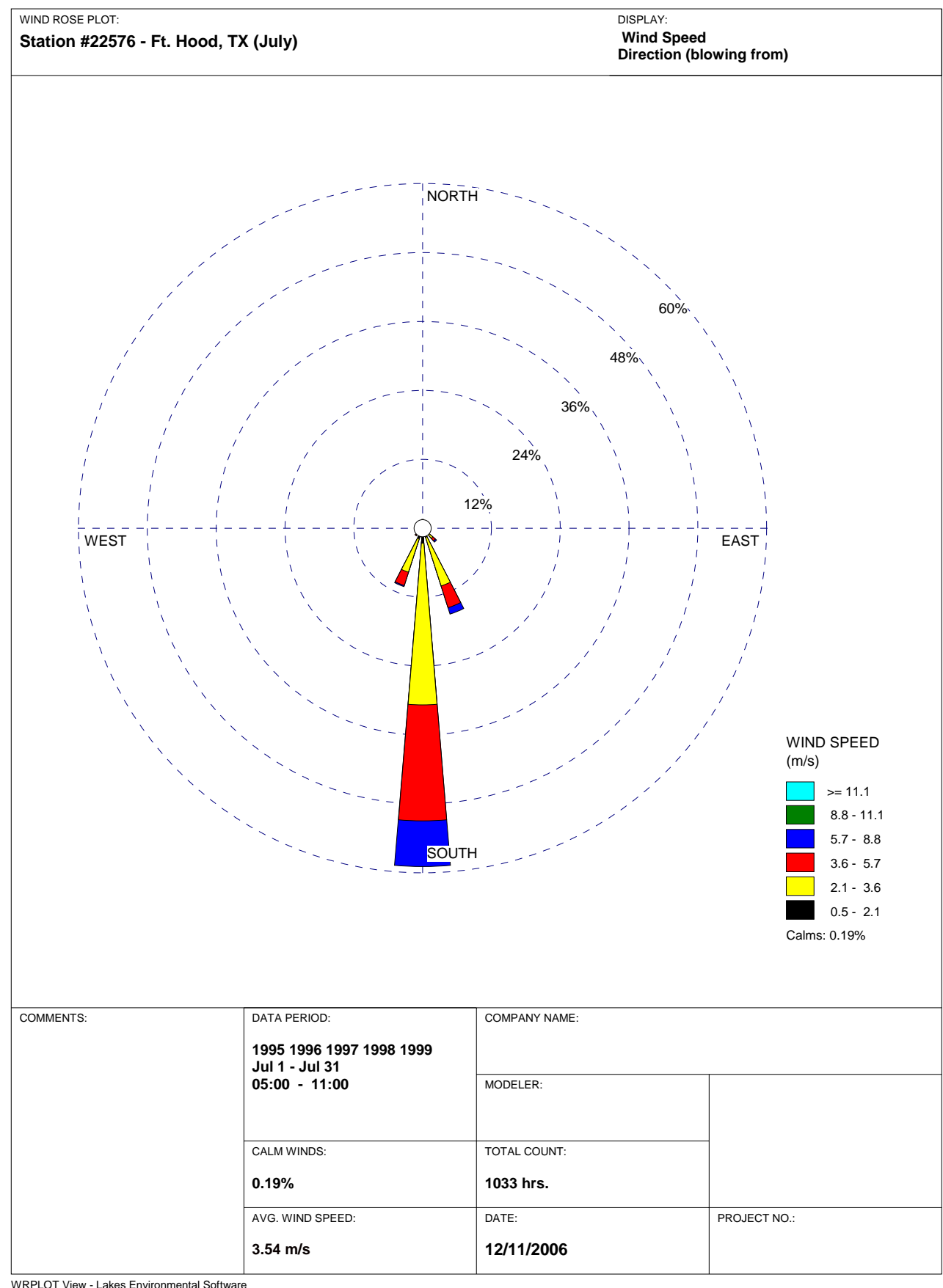

A. 5 


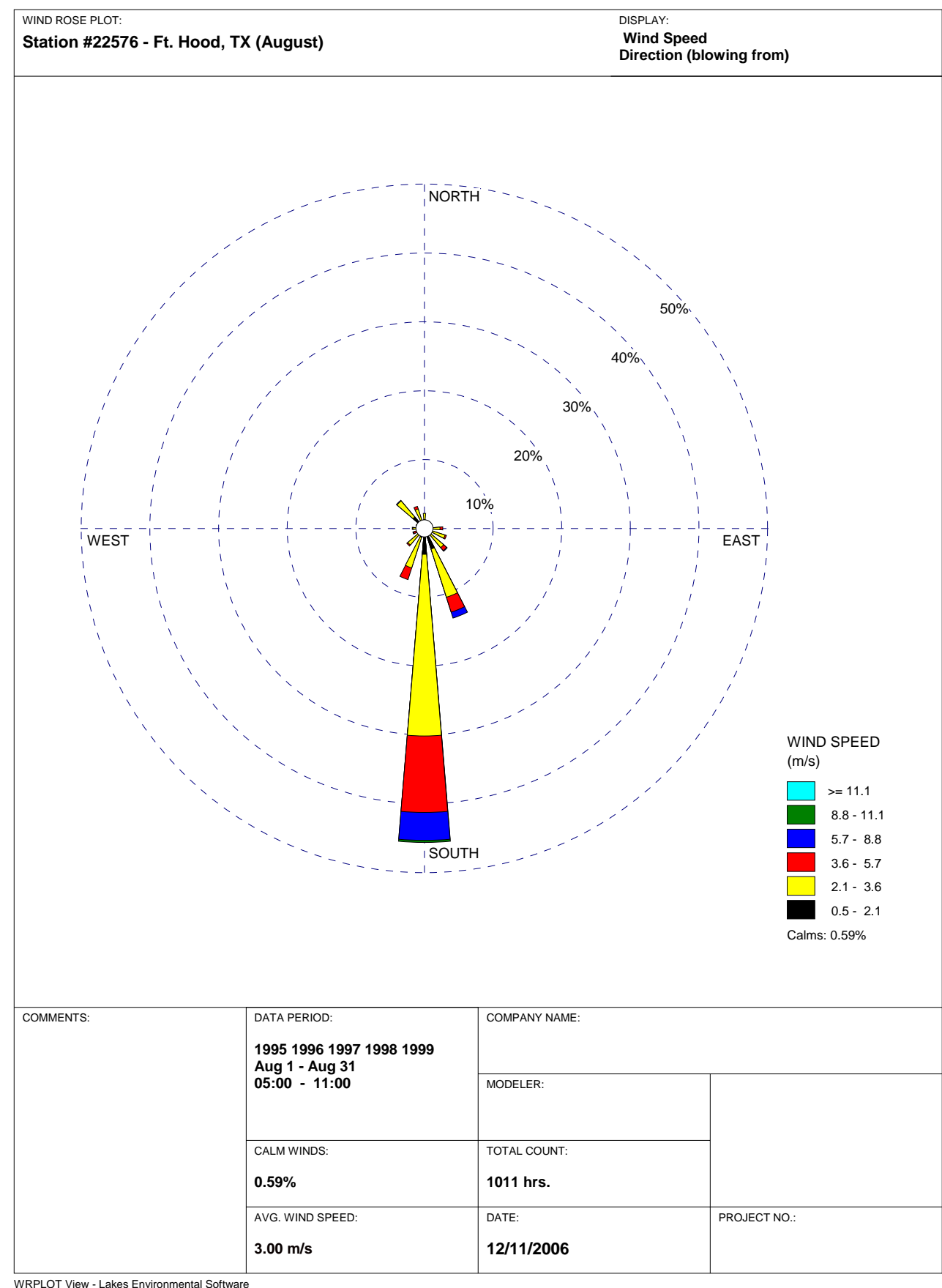

A. 6 


\section{Appendix B}

\section{Calculating the Shared Area Between Polygons}




\section{Appendix B-Calculating the Shared Area Between Polygons}

Plume contours generated by the DUSTRAN modeling system can be used, in conjunction with insect population polygons (see Section 5.3 for more information on creating insect population layers), to calculate the area shared between the polygons. This section presents a step-by-step procedure that can be used to calculate the shared area and is illustrative of how one might begin to quantify toxicological impacts from FO releases. As detailed in the steps below, this analysis is performed largely using tools and techniques that are native to the ArcMap interface; however, concentration contours generated by DUSTRAN will first need to be converted from polylines to polygons. Polygons allow for the direct calculation of the area shared by a plume and insect population contours. In the steps that follow, a thirdparty GIS extension called XTOOLS was used for converting concentration contours from polylines to polygons; the tool used in this example is available for from Data East and can be downloaded at: http://www.xtoolspro.com. Other vendors have developed comparable tools for performing such a conversion.

The following steps detail how to calculate the area shared by a plume contour and insect population layer, from which the impacted insect population can be quantified. A layer called "InsectPopulation" is assumed have already been created in the Layer Creator utility (see Section 5.3) and contains population polygons for a specific insect type.

1. After an FO simulation has been performed in DUSTRAN, double-click on the "Simulation" layer in the ArcMap "Table of Contents" window. The "Layer Properties" window will appear; click on the “Definition Query” tab (see Figure B.1).

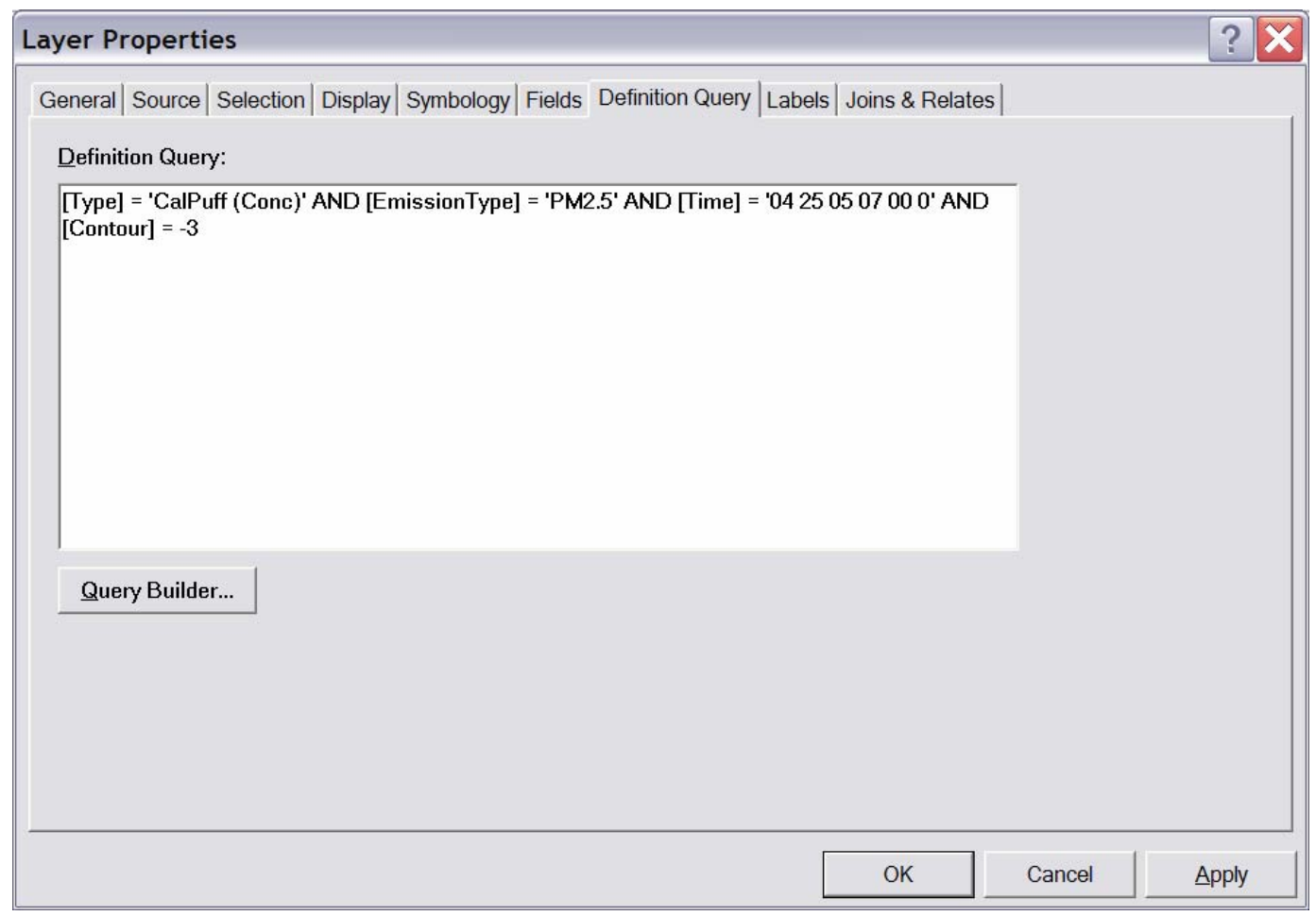

B.1 
Figure B.1. Example “Layer Properties” Window with the "Definition Query” Tab Display

2. The "Query Builder" option on the "Definition Query" tab is used to select the desired concentration contour using a query statement of the following format:

[Type] = 'CalPuff (Conc)' AND [EmissionType] = 'PM2.5' AND [Time] = '04 25050700 0' AND [Contour $]=-3$

The categories used in the query statement to select the desired contour level correspond to values listed on the "Contours" tab of the DUSTRAN interface. Figure B.2 displays a sample "Contours" tab and how the parameters listed on the tab relate to categories in the query selection statement.

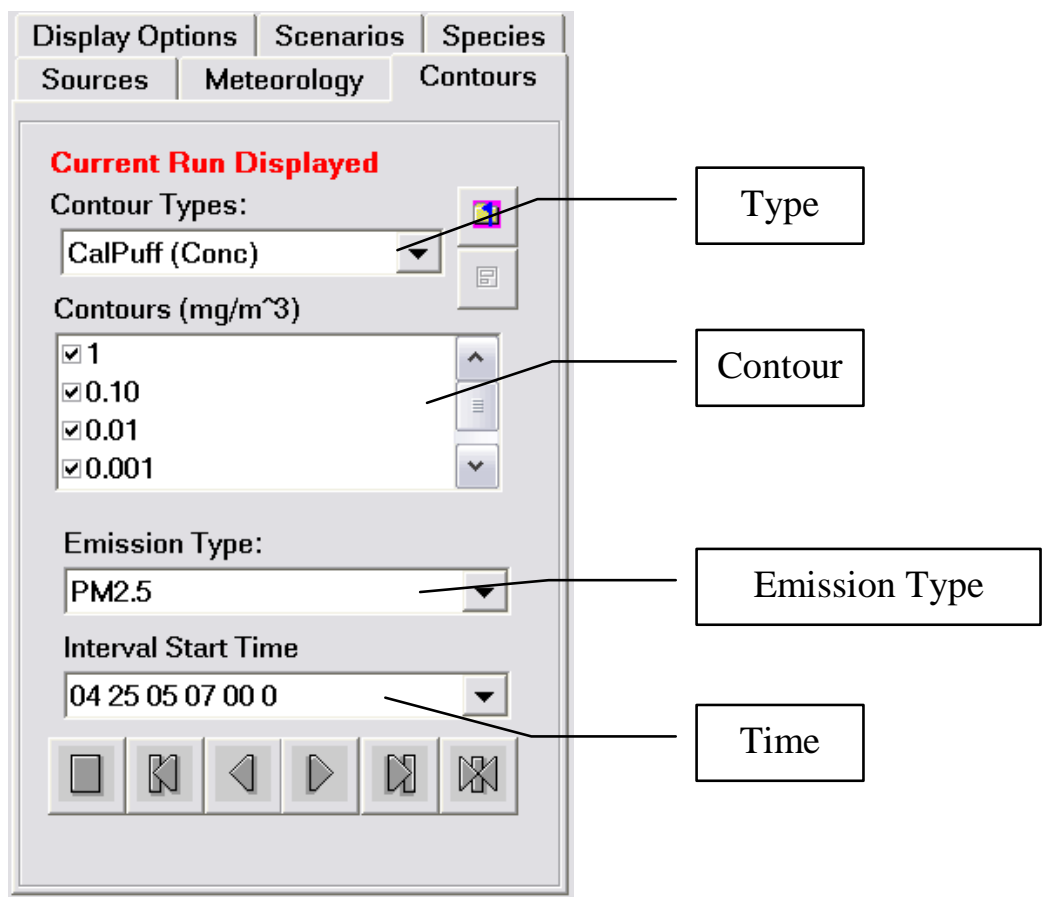

Figure B.2. DUSTRAN “Contour” Tab Used to Define Values for the Definition Query

Note that contour mass units specified in the query selection are always in grams (g); DUSTRAN contours are in mass units specified in the Cal.par file (see Section 5.1) and may be different. Therefore, the correct mass conversion must be supplied in the selection query. In the above query (Figure B.1), the contour being selected is $1.0 \mathrm{E}-3 \mathrm{~g} / \mathrm{m}^{3}\left(1.0 \mathrm{mg} / \mathrm{m}^{3}\right)$.

3. Once the contour has been selected using the "Definition Query," the contour can be converted from a polyline shape to a polygon shape. If the XTOOLS extension is being used for the conversion, the polyline-to-polygon conversion is performed using the "Make One Polygon from Polylines" option from the "Feature Conversions" menu. 
4. After the contour has been converted from a polyline to a polygon, the insect population polygons can be clipped against the contour polygon. From the ArcMap application interface, open the ArcToolbox application.

5. In the ArcToolbox menu, select the "Clip" option under the "Extract" option of the "Analysis Tools" menu.

6. In the "Clip" window that is displayed, select the layer to be clipped (e.g., BugPopulation) and the layer to clip against (concentration contour). Enter a path and name for the shapefile that will be created as the result of the clipping operation. Figure B.3 displays an example of the "Clip" window with selections visible. Click on the "OK" button; a new layer will be created and added to the map display and table of contents within the ArcMap interface.

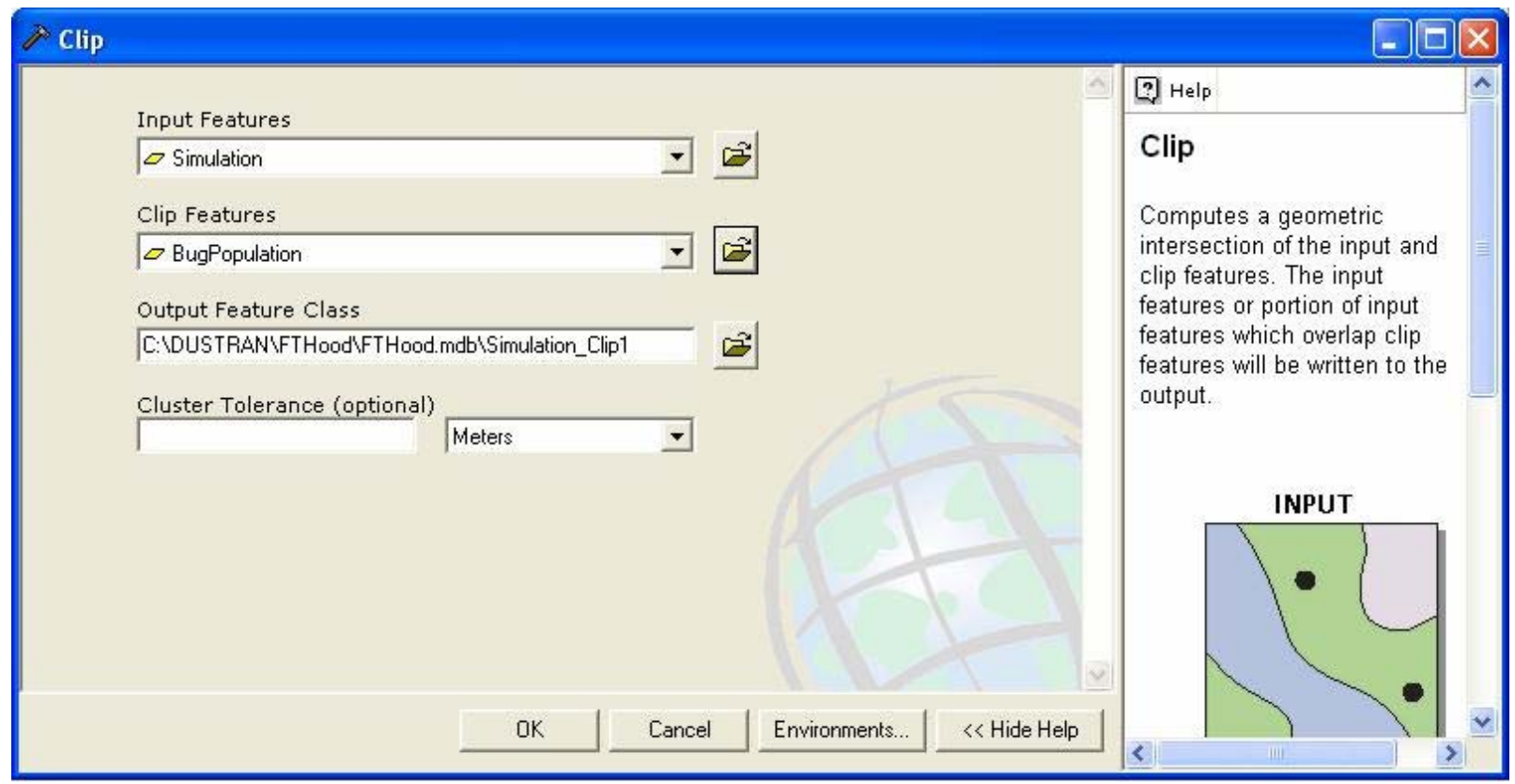

Figure B.3. Example Clip Window with Input and Clip Features Selected

7. The area of the new polygons will now need to be calculated and added to the clipped file. Open the attribute table of the clipped layer by clicking on the layer's name in the table of contents and clicking on the "Open Attribute Table" option in the drop-down menu.

8. Once the attribute table has opened, click on the "Options" button and then select the "Add Field" option from the menu that is displayed.

9. In the "Add Field" window that is displayed, enter a name for the new field and a data type. For the area calculations, "Double” should be selected as the data type for the new field.

10. With the new field entered into the attribute table, left-click on the new field header to select the field column. Right-click on the header name of the new field and select the "Calculate Values" option from the drop-down menu. 
11. In the "Field Calculator" window, select the "Advanced" option on the form and then enter the following code into the "Pre-Logic Visual Basic for Applications (VBA) Script Code” panel:

Dim Output as double

Dim pArea as Iarea

Set pArea $=[$ shape $]$

Output $=$ pArea.area

12. In the entry box below the "Pre-Logic VBA Script Code" window, enter the word "Output." Clicking on the "OK" button will result in the areas of the polygons being calculated and automatically entered into the new field of the attribute table. Figure B.4 shows an example of the "Field Calculator" window with the VBA script code entered.

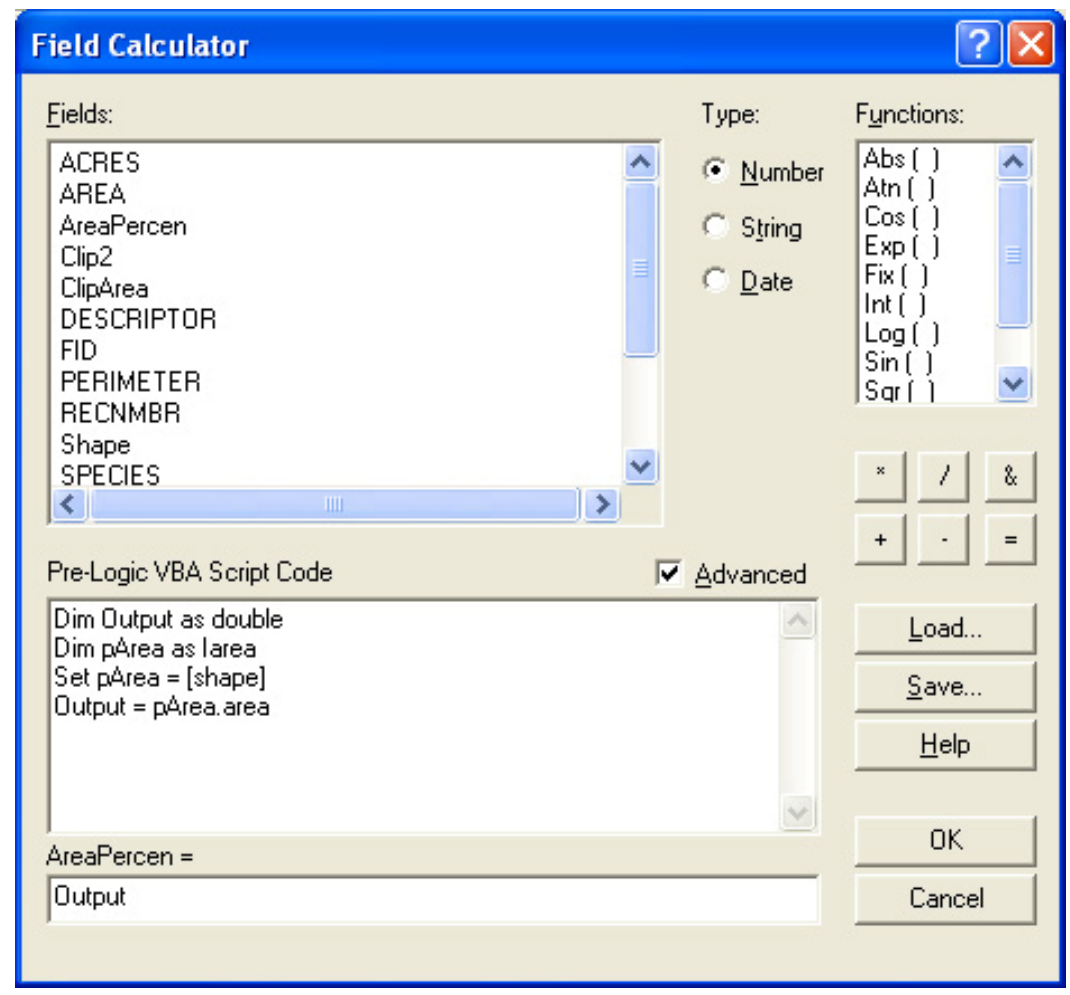

Figure B.4. Example “Field Calculator” Window with VBA Code Entered

13. Once the area has been calculated, the clipped layer needs to be joined with the original layer. Rightclick on the name of the clipped layer in the table of contents and select the "Join" option in the "Joins and Relates" menu.

14. In the "Join Data" window, select the "Join attributes from a table" option in the "What do you want to join to this layer?” selection box.

15. In the first selection box, select the Feature ID (FID) option. In the second selection box, select the layer from which the clipped areas were taken. Finally, in the third selection box, select the FID 
option. Figure B.5 shows an example of the "Join Data" window with the appropriate selections made:

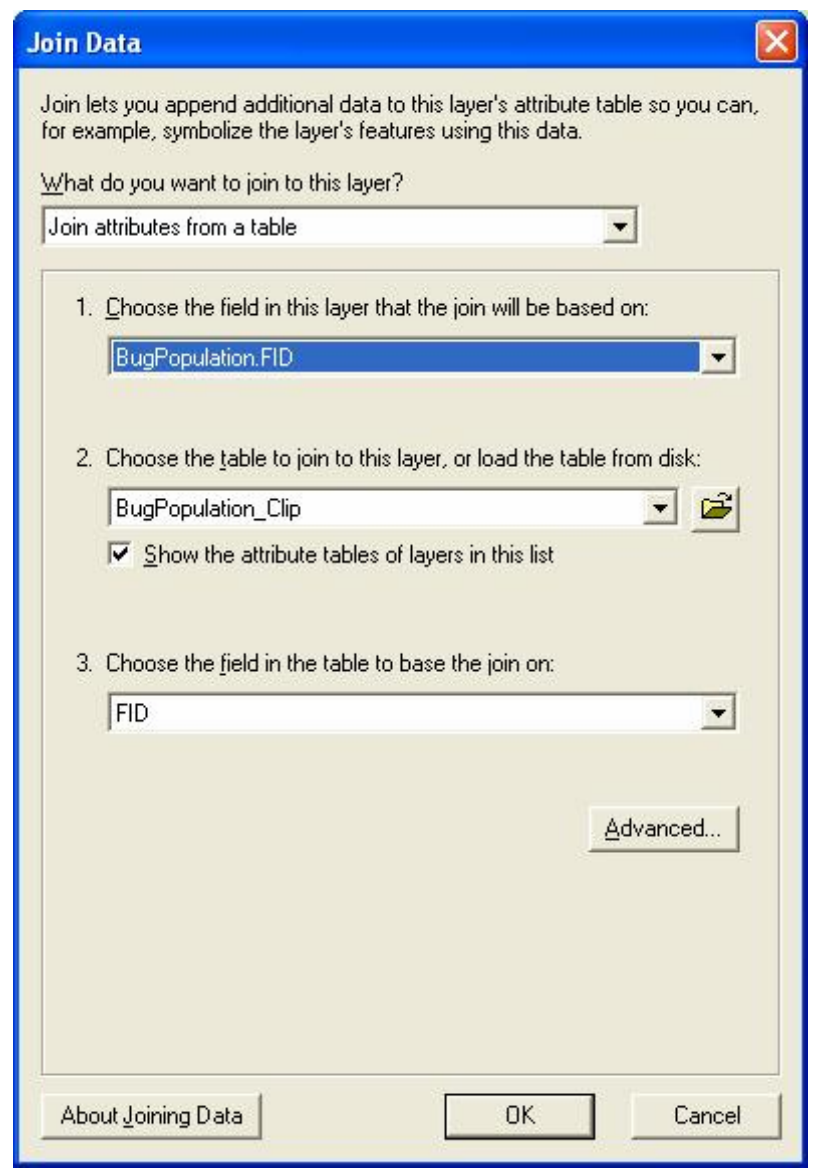

Figure B.5. Example “Join Data” Window

16. Click on the "OK" button to perform the join and close the "Join Data" window. Attributes from the original unclipped layer will be added to the fields of the clipped layer. All field names will be prefixed with the name of the layer from which they are stored.

17. With the join operation completed, open the attribute table of the clipped layer by right-clicking on the layer's name in the table of contents and selecting the "Open Attribute Table" option.

18. In the attribute table window, select the "Add Field” option from the "Options” menu.

19. Set the field name and type in displayed "Add Field" window. Set the type of the new field to "Double."

20. Left-click on the name header of the new field to select the field column and then right-click on the header to select the "Calculate Values" from the drop-down menu.

21. Using the "Field Calculator" window that is displayed, enter the calculation of the clipped area divided by the original full area and then click on the "OK" button. 
22. Once the "OK" button has been clicked, the software will automatically calculate the area percentages and fill in the column. 
PNNL-16321

\section{Distribution}

No. of

Copies

OFFSITE

2 Matt Hohmann

ERDC-CERL

PO Box 9005

Champaign, IL 61826-9005

1-800-872-2375 ext. 5863
No. of

Copies

ONSITE

7 Pacific Northwest National Laboratory

K. J. Allwine

K9-30

E. G. Chapman K9-30

C. J. Driver K2-21

J. P. Rishel K9-30

F. C. Rutz 6-52

Information Release (2) P8-55

Distr. 1 